Research Article

\title{
Failure Mechanism of a Coal-Rock Combined Body with Inclinations of Structural Planes and a Calculation Model for Impact Energy
}

\author{
Yi-Chao Zhao $\mathbb{D}^{1,2}$ Ming-Shi Gao $\mathbb{D}^{1},{ }^{1,2,3}$ Yong-Liang $\mathrm{He},{ }^{1,2}$ and Dong $\mathrm{Xu}^{1,2}$ \\ ${ }^{1}$ School of Mines, China University of Mining and Technology, Xuzhou 221116, China \\ ${ }^{2}$ Key Laboratory of Deep Coal Resource Mining (CUMT), Ministry of Education of China, \\ China University of Mining and Technology, Xuzhou 221116, China \\ ${ }^{3}$ College of Geology and Mineral Engineering, Xinjiang University, Urumqi 830047, China \\ Correspondence should be addressed to Ming-Shi Gao; cumt_gms@cumt.edu.cn
}

Received 25 July 2019; Revised 16 September 2019; Accepted 15 November 2019; Published 17 December 2019

Academic Editor: Zhongguo John Ma

Copyright (C) 2019 Yi-Chao Zhao et al. This is an open access article distributed under the Creative Commons Attribution License, which permits unrestricted use, distribution, and reproduction in any medium, provided the original work is properly cited.

\begin{abstract}
A coal-rock (CR) combined body can be used to simulate structures of coal and rock strata, and its impact-induced failure characteristic conforms more close to engineering practice. Exploring the mechanical properties and impact energy in a CR combined body contributes to better predictions of rock bursts in coal mines. In the study, the mechanical properties of $\mathrm{CR}$ combined bodies with four different inclinations $\left(0^{\circ}, 15^{\circ}, 30^{\circ}\right.$, and $\left.45^{\circ}\right)$ of structural planes were measured, and also their failure mechanism was analysed. Based on the theory of particle mechanics, a calculation model for impact energy in a CR combined body with inclinations was established and then verified by using monitored acoustic emission (AE) data. The test results showed that inclination affected mechanical properties and failure characteristics of the CR combined body, i.e., the larger the inclination, the lower the strength and impact energy in the CR combined body and the lower the level of damage. The proposed calculation model for impact energy revealed the mechanical essence of energy accumulation and release of a CR combined body, providing a reference for investigating rock burst in coal mines.
\end{abstract}

\section{Introduction}

Rock bursts in coal mines are a dynamic disaster induced by failure of coal and rock masses and release much energy $[1,2]$. Mechanical properties of coal and rock masses are considered to be the basis for exploring rock bursts in coal mines [3,4]. At present, the mechanical parameters and impact-induced failure characteristics of coal and rock are generally tested by applying stress on pure coal (PC) and pure rock (PR) specimens; however, mining spaces are integral structures composed of CR combined bodies. If only PC and PR are separately investigated, structural planes and interaction of coal and rock masses will be ignored, therefore, mechanical properties and failure process of PC and PR specimens fail to reflect the actual condition of failure [5]. Additionally, a CR combined body contains two materials, and the calculation method for the impact energy in the CR combined body certainly differs from that for PC and PR. Hence, exploring the impact-induced failure and energy evolution of a CR combined body is conducive to investigating the generation of rock bursts in coal mines.

To explore the mechanical essence of accumulation and release of impact energies in a CR combined body, it is necessary to first investigate the mechanical properties and failure mechanism of CR combined specimens (Figure 1). By measuring the mechanical properties of $\mathrm{CR}$ combined specimens, Liu et al. [6] investigated the effect of material strength on failure mode of specimens. Wang and $\mathrm{Du}$ [7] measured the mechanical properties of a CR combined body under unloading conditions and found that a CR combined body is more prone to deformation and failure during unloading. Du et al. [8] studied the mechanical properties of 


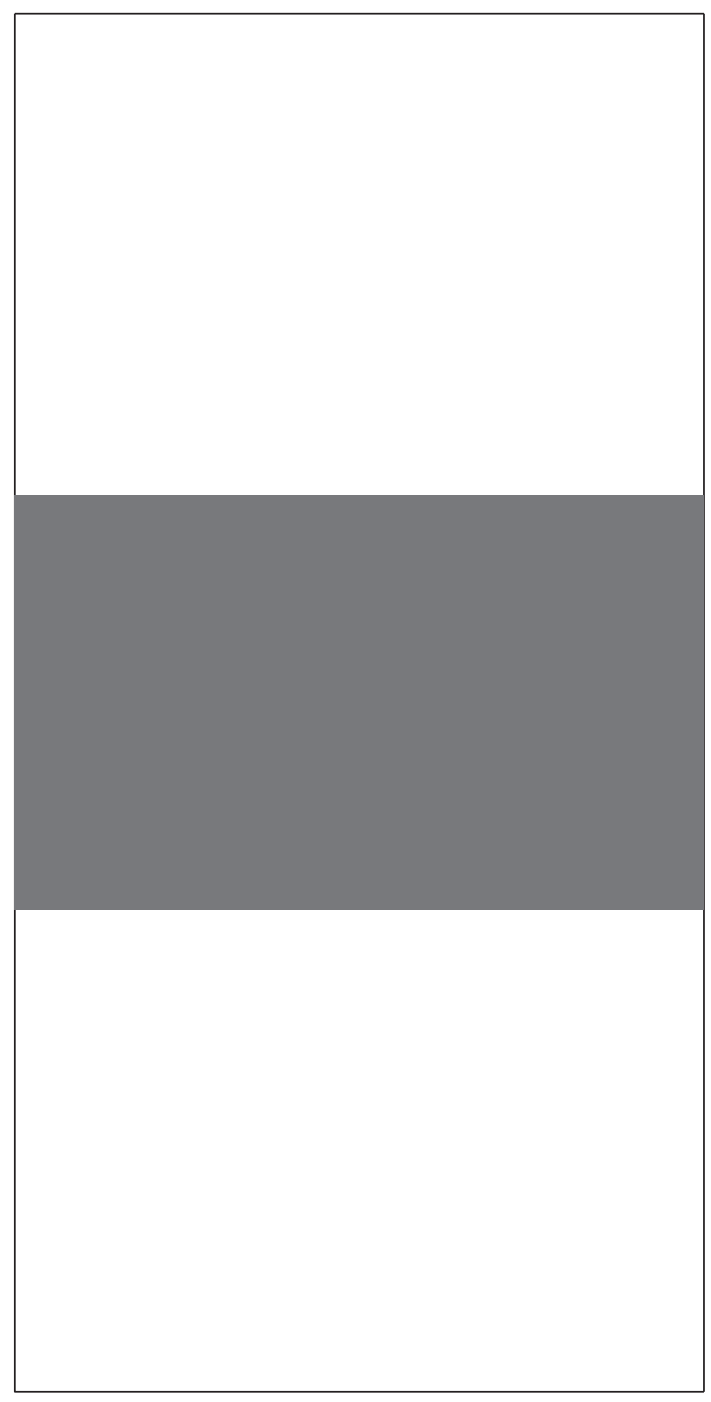

(a)

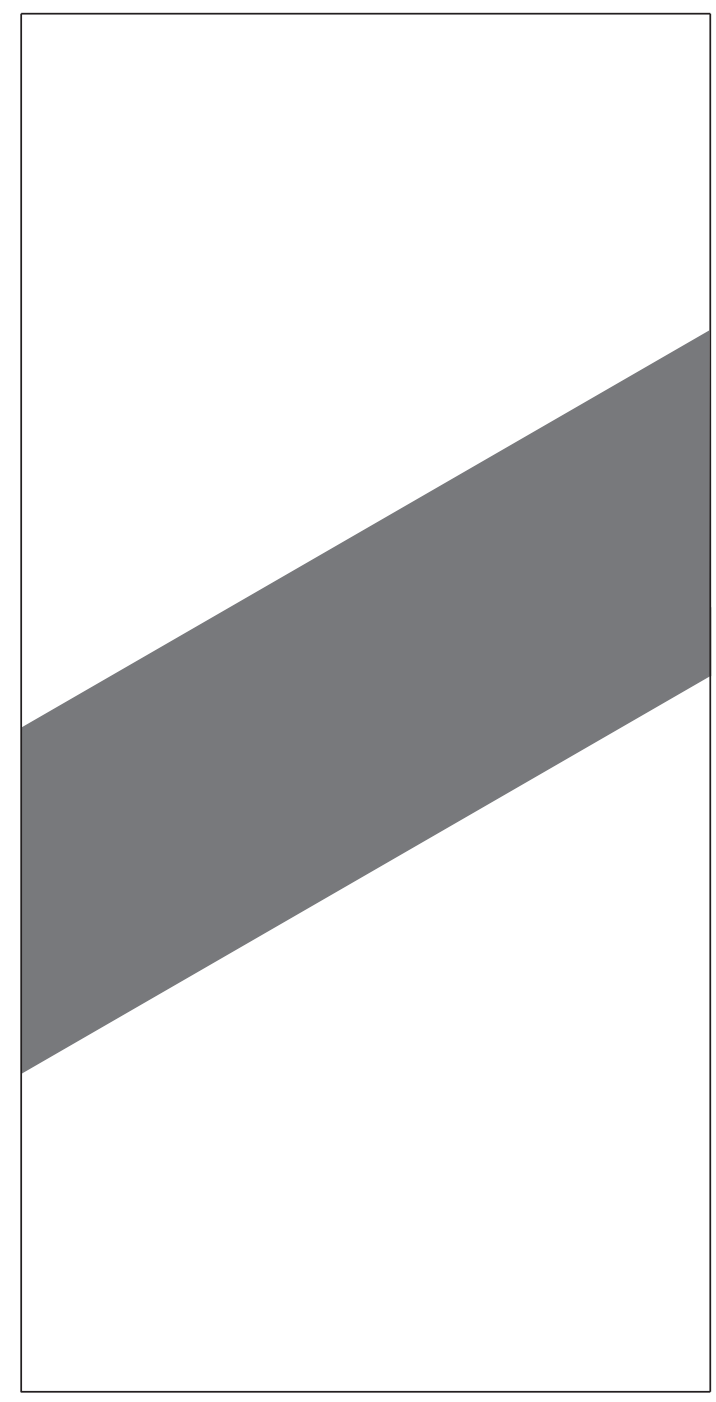

(b)

FIGURE 1: CR combined specimens (a) without inclination and (b) with inclinations.

a CR combined body containing gas, and the results demonstrate that a CR combined body has a higher strength than PC and expands outwards upon unloading. Liu et al. [9] measured the mechanical properties of a CR combined body and established the corresponding damage constitutive model thereof. Huang and Liu [10] discussed various mechanical behaviours of $\mathrm{CR}$ combined specimens under different loading rates. Guo et al. [11] measured strengths of a CR combined body with various inclinations of its structural planes and described the failures therein. The aforementioned research is expected to provide a reference for measurement of the mechanical properties of a CR combined body in the laboratory.

Two methods (laboratory monitoring and numerical simulation) are frequently applied in such research into the energy release from coal and rock masses [12-21]. By monitoring the acoustic emission (AE) energy in coal masses during loading and unloading, Wang et al. [22] found that energy release of coal masses is related to the fractures therein. Meng et al. [23] suggested that energy release is correlated with loads while being unrelated to loading rate by monitoring $\mathrm{AE}$ events under uniaxial load. By utilising PFC numerical simulation software, Lin et al. [24] investigated the crack propagation and energy release in coal masses under different lateral pressure coefficients. By using PFC numerical simulation software, Jin et al. [25] discussed the effect of initial cracks on energy release in rocks and found that the energy released from rock approximately rises with increasing angle of cracks to the loaded axis. Additionally, some scholars also investigated the energy release from a CR combined body. Lu et al. [26] discussed the energy release and vibrational characteristics of a CR combined body by using a microseismic monitoring instrument. The result showed that the vibrational signals recorded before impact-induced failure exhibit remarkable precursory characteristics indicative of a rock burst. Tan et al. [27] explored the effect of the homogeneity of a CR combined body on AE energy by PFC numerical simulation 
software. The result indicated that the stronger the homogeneity of coal and rock masses, the larger the rock burst tendency of a CR combined body. The aforementioned research indicates that structure of a CR combined body, loading mode, and material characteristics affect the failure and energy release of coal and rock.

Above all, failure characteristics of a CR combined body are more consistent with engineering practice. Therefore, exploring the failure characteristics and impact energies of a CR combined body is conducive to revealing the evolution of a rock burst in coal mines. In the study, mechanical properties of CR combined bodies were tested, and its failure mechanism were analysed. Failure process of the specimens was monitored through the use of an AE monitoring system and high-speed photography $[28,29]$. Furthermore, a calculation model for impact energies in a CR combined body with inclinations was proposed to reveal the mechanical essence of the energy release. The results can provide new ideas and methods for exploring and predicting rock bursts in coal mines.

\section{Test Process}

2.1. Preparation of Specimens. Coal mass and rock used in the test were taken from coal seams and roof strata, with strong rock burst tendency, in a coal mine in Inner Mongolia Autonomous Region, China. The fundamental mechanical properties of materials are listed in Table 1. The structures of the $\mathrm{CR}$ combined body are displayed in Figure 2. The specimens measured $50 \mathrm{~mm} \times 50 \mathrm{~mm} \times 100 \mathrm{~mm}$, and the thickness $\delta$ of each coal section was $20 \mathrm{~mm}$. CR combined specimens were bonded with a resin-anchoring agent for bolts used in mines. The serial number of the specimens was represented by a combination of sample types (CR, PC, and PR refer to CR combined specimens, pure coal specimens, and pure rock specimens, respectively), inclinations $\alpha$ (i.e., $0-0^{\circ}, 15-15^{\circ}, 30-30^{\circ}$, and $45-45^{\circ}$ ) of a coal section, and sequence number $(1,2$, or 3$)$. According to the characterisation requirements for specimens recommended by the International Society for Rock Mechanics and Rock Engineering (ISRMRE), the specimens were ground. The unevenness of the two end faces of the shaped specimens was less than $0.05 \mathrm{~mm}$, and the volumetric error was within $\pm 2500 \mathrm{~mm}^{3}$.

\subsection{Testing and Verification}

2.2.1. Test Method. A uniaxial compression test was carried out on the CR combined specimens along the axial direction. The axial stress on the specimens is expressed as follows:

$$
\sigma=\frac{P}{S}
$$

where $\sigma, P$, and $S$ denote axial stress (MPa), the load (N) applied, and cross-sectional area $\left(\mathrm{mm}^{2}\right)$ of the specimens, respectively. The axial strain on the coal section could be indirectly attained by measuring the amount of deformation of specimens and the strain on rock and expressed as follows [9]:

$$
\varepsilon_{\mathrm{c}}=\frac{\Delta l-\varepsilon_{\mathrm{r}} l_{\mathrm{r}}}{l_{\mathrm{c}}},
$$

where $\varepsilon_{c}, \Delta l$, and $\varepsilon_{r}$ represent the axial strain in a coal section, the amount (mm) of axial deformation of CR combined specimens, and axial strain in the rock, respectively; $l_{c}$ and $l_{r}$ denote the axial height $\left(l_{c}=\delta / \cos \right.$ $(\alpha) \mathrm{mm})$ of the coal section and axial height $\left(l_{x}=l-l_{c}\right)$ of the rock, respectively.

By monitoring the AE energy in the loading process, the cumulative $\mathrm{AE}$ energy is given by

$$
E_{\mathrm{AE}}=\sum e_{\mathrm{AE} i},
$$

where $E_{\mathrm{AE}}$ refers to the cumulative $\mathrm{AE}$ energy $(\mathrm{ms} \cdot \mathrm{mV})$ in specimens during the entire loading process and $E_{\mathrm{AE} i}$ represents the AE energy ( $\mathrm{ms} \cdot \mathrm{mV}$ ) of a single fracture event.

2.2.2. Equipment. An MTS-C64.106 electrohydraulic servo universal testing machine was used to apply load on the specimens; it had a maximum vertical load of $1000 \mathrm{kN}$ and a displacement resolution of $0.2 \mu \mathrm{m}$. The AE was monitored by employing a PCI-2 multichannel AE system. Moreover, the strain on the specimens was acquired by using an AKEMONDTSK-32-8C strain measuring instrument, with the resistance of all strain gauges being $120 \Omega$. The monitoring devices were connected as shown in Figure 3.

On condition that the strength of structural plane of coal and rock was too low, the specimens with a large inclination $\alpha$ would slide along the structural plane before being damaged. As a result, mechanical properties of CR combined specimens could not be attained. To prevent incorrect test data induced by slippage and failure of structural planes, two iron plates were fixed on the two sides of the specimens by using four screws, and also four axial force sensors were separately installed on a screw, as shown in Figure 4 . The sensor with the measurement range of 0 to $5 \mathrm{kN}$ had a sensitivity of $5 \%$ o $(25 \mathrm{~N})$. Before failure of a specimen, if the axial force on a single screw exceeded $50 \mathrm{~N}$, the specimen was supposed to slide, resulting in an erroneous test result. The spacing between the specimen and iron plate was between 1 and $2 \mathrm{~mm}$ so that the specimen was not affected by iron plates, and the $\mathrm{AE}$ sensor can remain in close contact with the surface of the specimen after crossing the iron plates.

2.2.3. Verification Methods. In the present study, load, strain, and AE energy were monitored. According to equation (1), the axial stress $\sigma$ on the specimens was calculated, and then the maximum axial stress is taken as the strength $\sigma_{\mathrm{cr}}$ of the specimens, that is, $\sigma_{\mathrm{cr}}=\max \{\sigma\}$. On this condition, the strengths of different specimens need to satisfy the following equation:

$$
V_{\sigma i}=\frac{\left|\sigma_{\mathrm{cr} i}-\overline{\sigma_{\mathrm{cr}}}\right|}{\overline{\sigma_{\mathrm{cr}}}} \times 100 \%<10 \%,
$$

where $V_{E i}, \sigma_{\mathrm{cri}}$, and $\overline{\sigma_{\mathrm{cr}}}$ refer to the coefficient of standard deviation of the strength of specimens, the strength $(\mathrm{MPa})$ of 
TABle 1: Mechanical properties of coal and rock.

\begin{tabular}{lccccccc}
\hline Material & $\begin{array}{c}\text { Uniaxial compressive } \\
\text { strength }(\mathrm{MPa})\end{array}$ & $\begin{array}{c}\text { Shear strength } \\
\left(10^{3} \mathrm{MPa}\right)\end{array}$ & $\begin{array}{c}\text { Dynamic failure } \\
\text { time }(\mathrm{ms})\end{array}$ & $\begin{array}{c}\text { Elastic energy } \\
\text { index }\end{array}$ & $\begin{array}{c}\text { Impact } \\
\text { energy index }\end{array}$ & $\begin{array}{c}\text { Elastic modulus } \\
\left(10^{3} \mathrm{MPa}\right)\end{array}$ & $\begin{array}{c}\text { Poisson's } \\
\text { ratio }\end{array}$ \\
\hline Coal & 24.97 & 7.97 & 34 & 7.75 & 8.91 & 6.72 & 0.31 \\
Rock & 46.91 & 16.56 & 152 & 14.14 & 11.42 & 12.34 \\
\hline
\end{tabular}

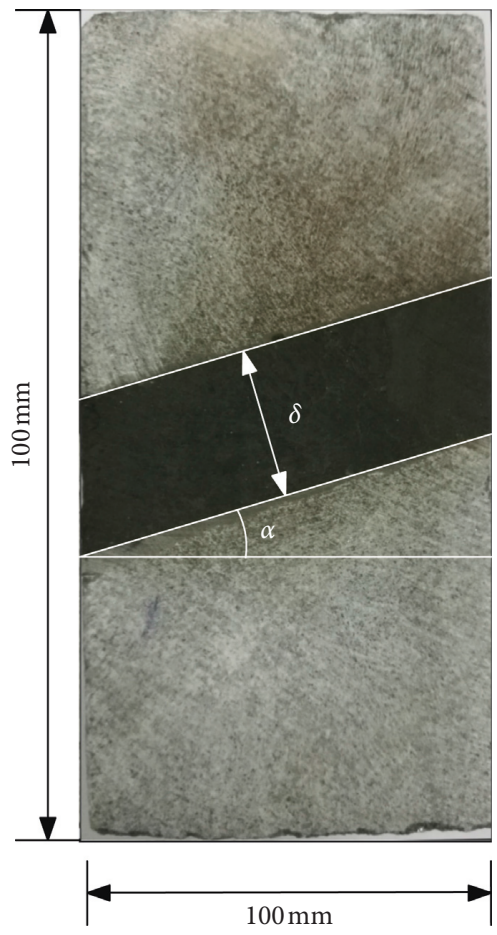

FIGURE 2: Photograph of a CR combined specimen with inclinations of structural planes.

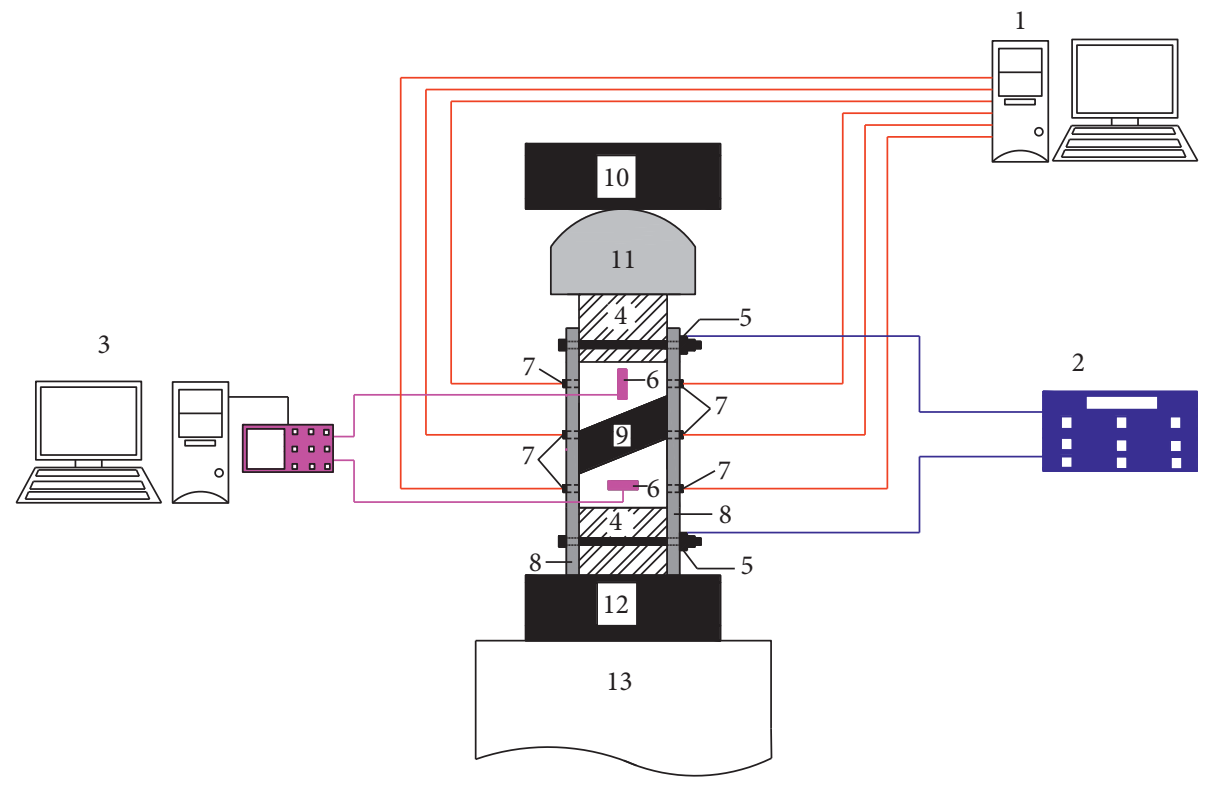

Figure 3: Loading monitoring system. 1, AE monitoring system; 2, monitoring system for axial force; 3, strain monitoring system; 4, iron ore; 5 , axial force sensor; 6 , strain gauge; 7 , AE sensor; 8 , iron plate; 9 , specimen; 10 , upper pressurised cylinder; 11 , steel prop to avoid eccentricity; 12 , lower pressurised cylinder; and 13, base of the press machine. 


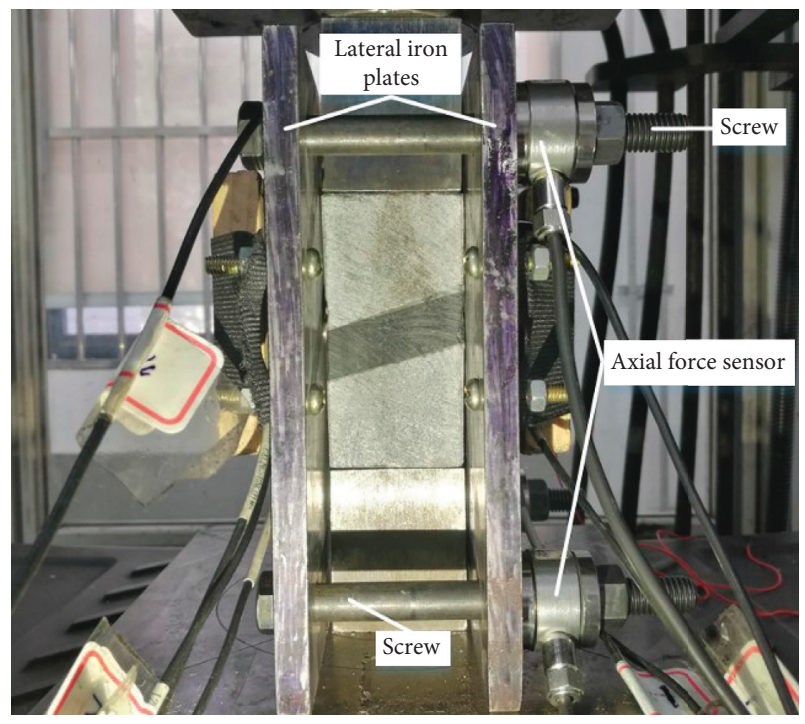

FIgURE 4: Iron plates and force sensors for monitoring lateral sliding.

specimens and the mean strength (MPa) of a group of specimens, respectively.

Eight $\mathrm{AE}$ sensors were fixed to the surfaces of all specimens. Afterwards, the cumulative AE energies in each channel were screened by using the following equation:

$$
V_{\mathrm{E} i}=\frac{\left|E_{\mathrm{AE} i}-\overline{E_{\mathrm{AE}}}\right|}{\overline{E_{\mathrm{AE}}}} \times 100 \%<10 \%,
$$

where $V_{E i}$ and $E_{\mathrm{AE} i}$ represent the coefficient of standard deviation of cumulative $\mathrm{AE}$ energy and cumulative $\mathrm{AE}$ energy $(\mathrm{ms} \cdot \mathrm{mV})$ of the $i$ th channel during the entire loading process, respectively; $\overline{E_{\mathrm{AE}}}$ denotes the mean $(\mathrm{ms} \cdot \mathrm{mV}) \mathrm{cu}-$ mulative $\mathrm{AE}$ energy in all channels. When the coefficient $V_{E i}$ of the standard deviation of cumulative AE energy in a certain channel does not satisfy equation (5), the monitoring result of the channel was eliminated, and the coefficient $V_{E i}$ of standard deviation of the cumulative $\mathrm{AE}$ energies in the other channels was calculated. No less than six sets of data should be involved in calculation here to prove satisfaction of equation (5); otherwise, it is considered that the monitoring data of AE energy were subject to significant errors.

\subsection{Test Procedure and Results}

2.3.1. Test Procedure. According to the recommendation of the International Society for Rock Mechanics and Stipulations in the Methods for Test, Monitoring, and Prevention of Rock Burst for the coal industry in China, a load-controlled method of testing was adopted. The specimens were subjected to the uniaxial loading test on the electrohydraulic servo universal testing machine, at the loading rate of $0.5 \mathrm{MPa} / \mathrm{s}(1.25 \mathrm{kN} / \mathrm{s})$ and the frequency of data acquisition of $1000 \mathrm{~Hz}$. By using the AE system, the AE energy in specimens was monitored, with the sampling frequency of $500 \mathrm{kHz}$, the threshold of $40 \mathrm{~dB}$, and a operating frequency of $100-400 \mathrm{kHz}$. Moreover, the PDT, HDT, and HLT were set to 50,200 , and $300 \mu \mathrm{s}$, respectively. The sampling frequency of the strain measuring instrument was $2 \mathrm{~Hz}$. In the test process, the failure process of specimens was recorded by using a NAC Memrecam HX-7s high-speed camera at a frequency of $1000 \mathrm{~Hz}$.

2.3.2. Test Results. The statistical parameters pertaining to the strength of the specimens are listed in Table 2. The coefficients of standard deviation of the strength on different specimens all satisfy equation (4). The cumulative AE energies during the entire loading process are listed in Table 3 , and the coefficients of standard deviation of cumulative $\mathrm{AE}$ energies in various specimens all satisfy equation (5). The strengths and cumulative AE energies in specimens with the same structures were consistent; this indicated that the initial cracks in rock and coal section had no significant effect on the test results, and the test method was thus verified as being effective.

2.3.3. Mechanical Properties. According to Table 2, it can be seen that the strength of CR combined specimens ranged from 12.5735 to $35.3115 \mathrm{MPa}$. With increasing inclination of structural planes, the strength of CR combined specimens declined. The strength of CR combined specimens differed from those of PC and PR, and inclination could directly determine the change in strength of $\mathrm{CR}$ combined specimens.

Figure 5 shows the stress-strain curves of specimens with different structures. PC specimens and CR combined specimens (Figures 5(a) and 5(c)-5(f)) underwent a significant compaction stage in the initial loading process, while PR specimens (Figure 5(b)) exhibited linear stressstrain behaviour.

The loading of a CR combined body could be divided into three stages: a compaction stage, an elastic stage, and a failure stage. The stress-strain curve in the compaction stage is wavy or arcuate. In this stage, initial microfractures in coal masses are closed, bringing the structure of the CR combined body to the stage of dynamic adjustment. The stressstrain curve in the elastic stage is an inclined line. In this stage, the CR combined body has a stable structure and accumulates much elastic energy. The failure stage appears at, and after, reaching peak stress. The stress-strain curves of CR combined specimens are similar to those of PC and PR specimens, all showing no residual strength. Due to the strong rock burst tendency of such a coal mass and its surrounding rock, CR combined specimens were suddenly fractured and damaged when loaded to their ultimate strength [30].

Parameters of deformation characteristics of each combined specimen are listed in Table 4 . With increasing inclination, the maximum strain of CR combined specimens decreased. When the inclination increased, the axial elastic modulus of the coal section decreased, while the axial elastic modulus and Poisson's ratio of the rock section increased. In other words, the greater the inclination, the lower the stiffness of the coal mass in such combined specimens, while the stiffer the rock mass. Compared with $\mathrm{CR}$ combined 
TABLE 2: Statistical results: strength of the specimens.

\begin{tabular}{lcccc}
\hline Serial number of specimens & $\sigma_{\mathrm{cr}}(\mathrm{MPa})$ & $V_{\sigma i}(\%)$ & Serial number of specimens & $\sigma_{\mathrm{cr}}(\mathrm{MPa})$ \\
\hline CR-0-1 & 32.1103 & -4.21 & CR-30-1 & 17.3016 \\
CR-0-2 & 33.1421 & -1.13 & CR-30-2 & -4.94 \\
CR-0-3 & 35.3115 & 5.34 & CR-30-3 & 19.3541 \\
Mean & 33.5213 & & Mean & 17.9453 \\
CR-15-1 & 25.9652 & -2.91 & CR-45-1 & 18.2003 \\
CR-15-2 & 28.2658 & 5.69 & CR-45-2 & 12.5735 \\
CR-15-3 & 26.0026 & -2.77 & CR-45-3 & 13.6984 \\
Mean & 26.7445 & & Mean & 12.8954 \\
PC-1 & 26.1556 & 4.75 & PR-1 & -3.69 \\
PC-2 & 24.5884 & -1.53 & PR-2 & 4.92 \\
PC-3 & 24.1654 & -3.22 & PR-3 & 48.0558 \\
Mean & 24.9698 & & Mean & 46.7412 \\
\hline
\end{tabular}

TABle 3: Statistical data: cumulative AE energies in specimens during the entire loading process.

\begin{tabular}{|c|c|c|c|c|c|}
\hline Serial number of specimens & $E_{\mathrm{AE}}(\mathrm{ms} \cdot \mathrm{mV})$ & $V_{\mathrm{E} i}(\%)$ & Serial number of specimens & $E_{\mathrm{AE}}(\mathrm{ms} \cdot \mathrm{mV})$ & $V_{\mathrm{E} i}(\%)$ \\
\hline CR-0-1 & 151889 & -5.7 & CR-30-1 & 62905 & -5.89 \\
\hline CR-0-2 & 158520 & -1.59 & CR-30-2 & 72354 & 8.25 \\
\hline CR-0-3 & 172820 & 7.29 & CR-30-3 & 65258 & -2.37 \\
\hline Mean & 161076 & & Mean & 66839 & \\
\hline CR-15-1 & 111559 & -7.87 & CR-45-1 & 41604 & -4.89 \\
\hline CR-15-2 & 131118 & 8.28 & CR-45-2 & 47265 & 8.05 \\
\hline CR-15-3 & 120595 & -0.41 & CR-45-3 & 42365 & -3.15 \\
\hline Mean & 121091 & & Mean & 43745 & \\
\hline PC-1 & 112247 & 3.58 & PR-1 & 316279 & 4.39 \\
\hline PC-2 & 108554 & 0.17 & PR-2 & 307146 & 1.38 \\
\hline PC-3 & 104295 & -3.76 & PR-3 & 285494 & -5.77 \\
\hline Mean & 108365.33 & & Mean & 302973 & \\
\hline
\end{tabular}

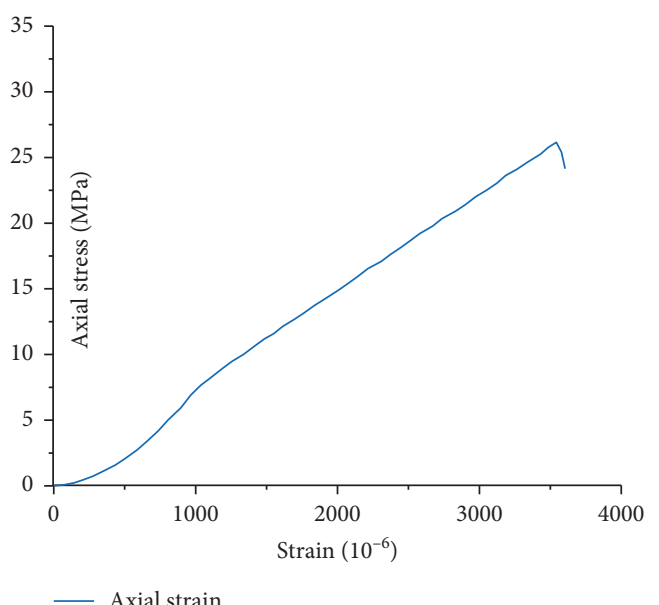

(a)

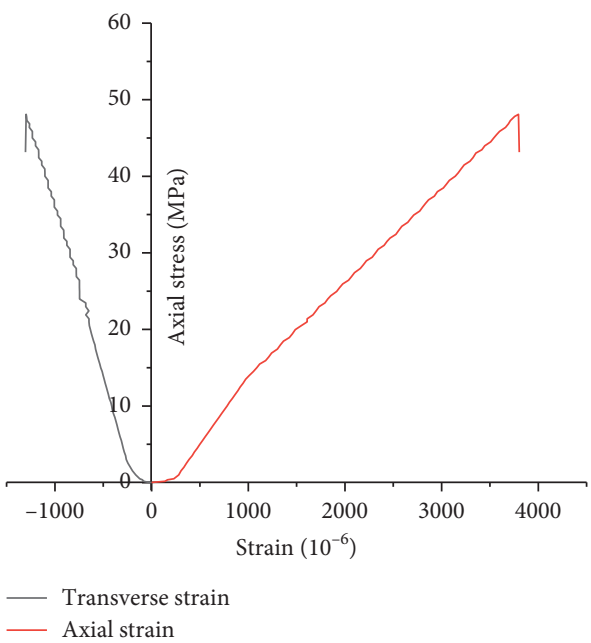

(b)

Figure 5: Continued. 


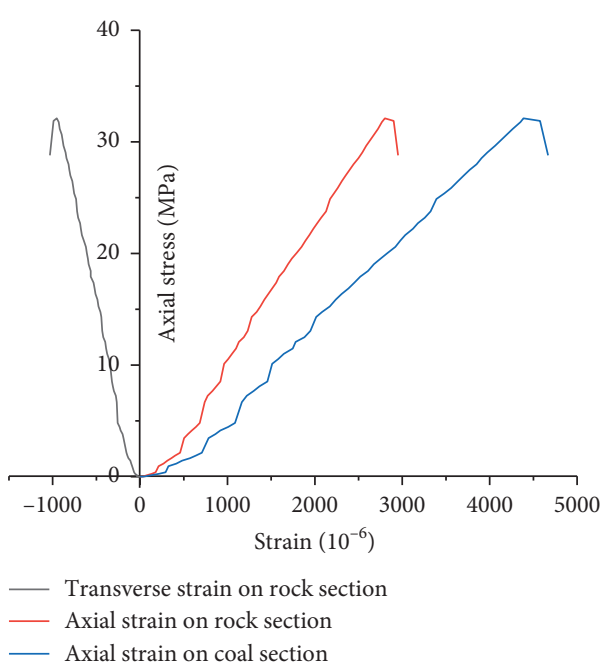

(c)

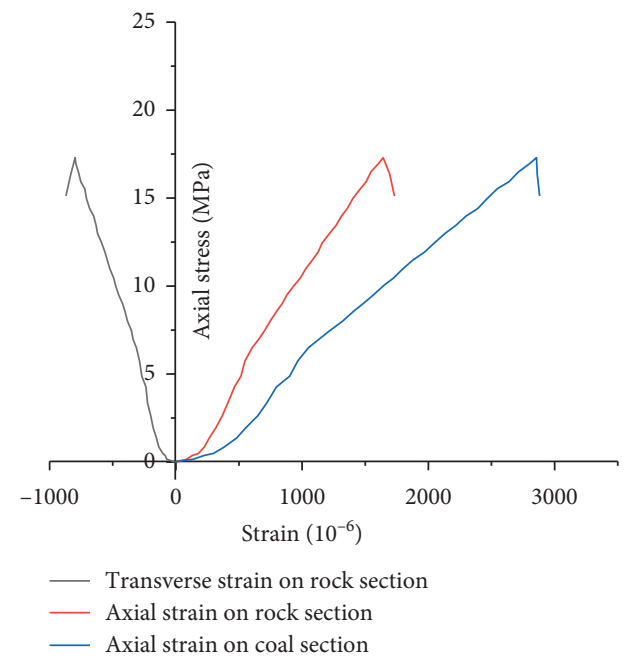

(e)



- Transverse strain on rock section

— Axial strain on rock section

— Axial strain on coal section

(d)

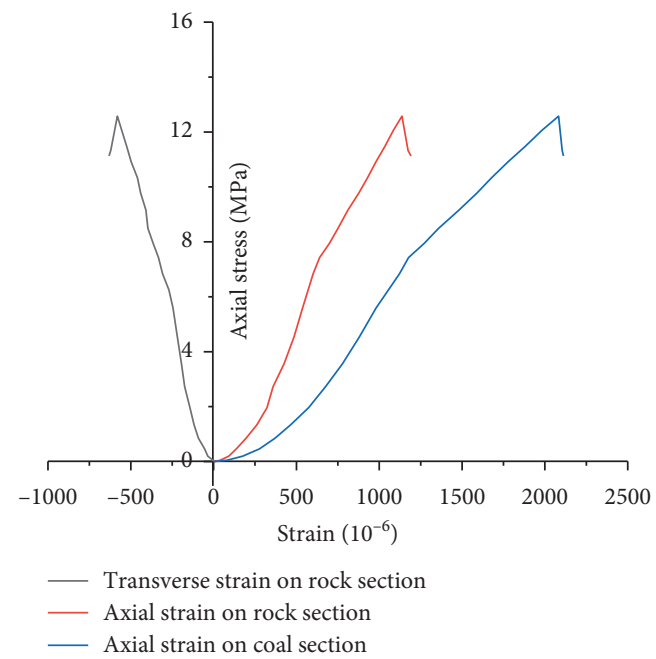

(f)

FIGURE 5: Stress-strain curves of specimens with different structures: (a) PC specimens; (b) PR specimens; (c) CR combined specimens with $\alpha=0^{\circ}$; (d) CR combined specimens with $\alpha=15^{\circ}$; (e) CR combined specimens with $\alpha=30^{\circ}$; (f) CR combined specimens with $\alpha=45^{\circ}$.

TABle 4: Deformation characteristics of CR combined specimens.

\begin{tabular}{|c|c|c|c|c|c|c|c|c|}
\hline $\begin{array}{l}\text { Serial number of } \\
\text { different groups of } \\
\text { specimens }\end{array}$ & $\begin{array}{c}\text { Maximum axial } \\
\text { strain in } \\
\text { specimens } / 10^{-6}\end{array}$ & $\begin{array}{c}\text { Variation } \\
(\%)\end{array}$ & $\begin{array}{c}\text { Axial elastic } \\
\text { modulus of coal } \\
\text { section }(\mathrm{GPa})\end{array}$ & $\begin{array}{c}\text { Variation } \\
(\%)\end{array}$ & $\begin{array}{c}\text { Axial elastic } \\
\text { modulus of rock } \\
\text { section }(\mathrm{GPa})\end{array}$ & $\begin{array}{c}\text { Variation } \\
(\%)\end{array}$ & $\begin{array}{l}\text { Poisson's } \\
\text { ratio of } \\
\text { rock section }\end{array}$ & $\begin{array}{c}\text { Variation } \\
(\%)\end{array}$ \\
\hline CR-0 & 2543 & 0 & 7.32 & 0 & 10.73 & 0 & 0.33 & 0 \\
\hline CR-15 & 2027 & -20.29 & 6.85 & -6.42 & 10.89 & 1.49 & 0.41 & 24.24 \\
\hline CR-30 & 1510 & -40.62 & 6.2 & -15.3 & 11.16 & 4.01 & 0.47 & 42.42 \\
\hline CR-45 & 1068 & -58 & 6 & -18.03 & 11.56 & 7.74 & 0.48 & 45.45 \\
\hline
\end{tabular}

specimens with an inclination of $0^{\circ}$, the coal section and rock section in $\mathrm{CR}$ combined specimens with an inclination of $45^{\circ}$ exhibited the most significant changes in mechanical properties; the axial elastic modulus and Poisson's ratio of the rock section separately increased by $7.74 \%$ and $45.45 \%$, while the axial elastic modulus of coal section decreased by $18.03 \%$; therefore, the greater the inclination, the more the mechanical properties of such a coal mass were weakened, which led to a lower stiffness of the CR combined body.

2.3.4. Failure Characteristics. The corresponding relationships between AE energy and axial stress on specimens with 




- AE energy

- Curve of cumulative AE energy

(a)

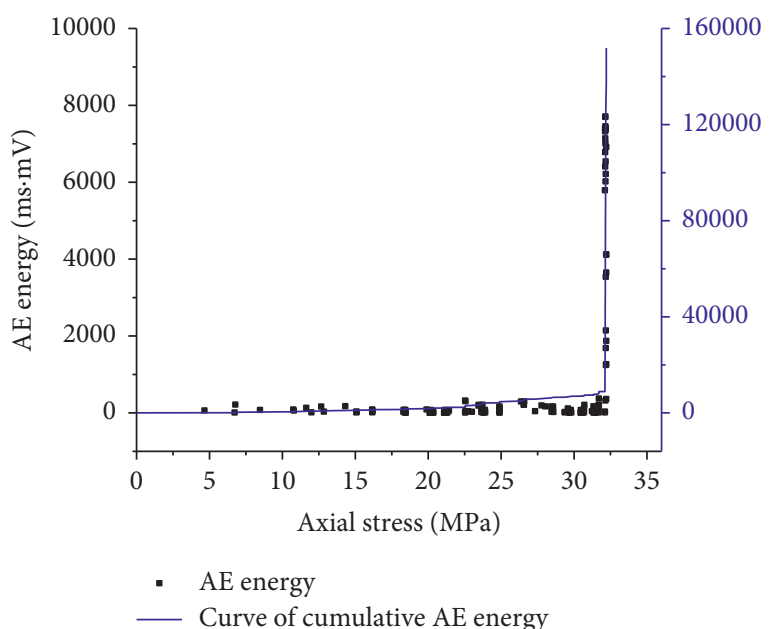

(c)



(e)

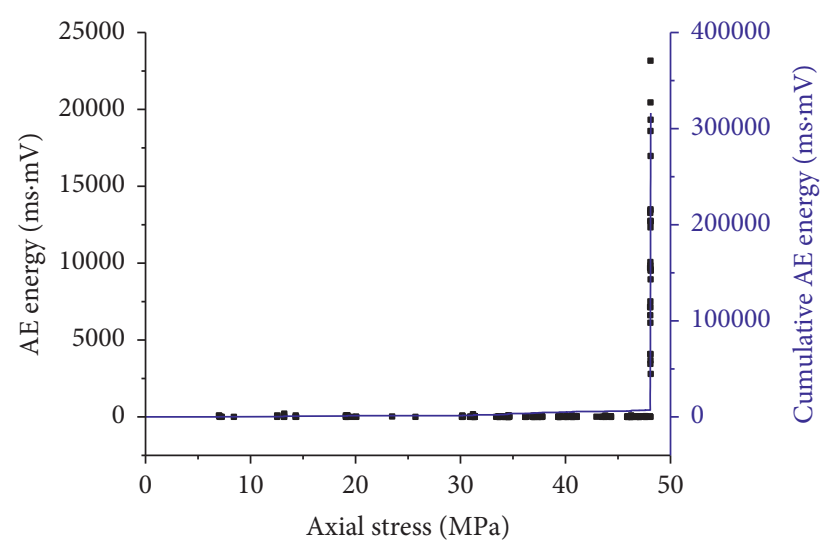

- AE energy

- Curve of cumulative AE energy

(b)

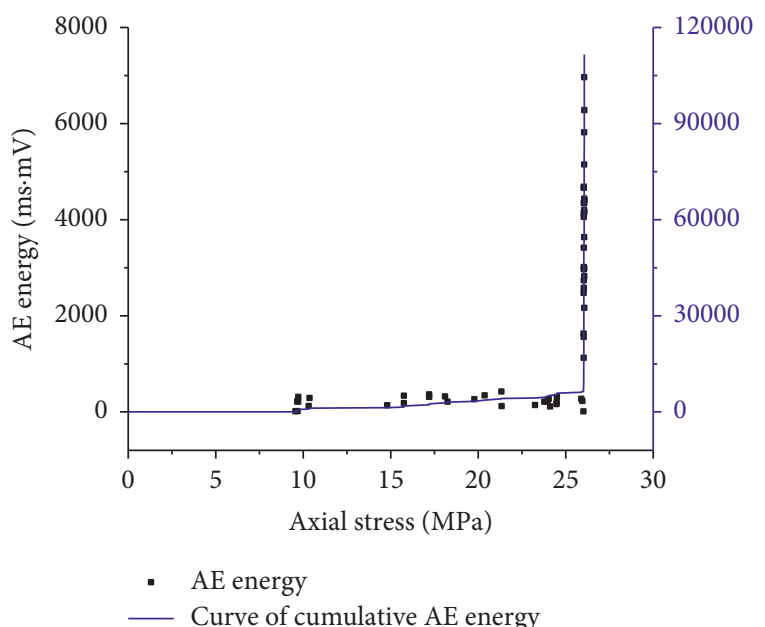

(d)

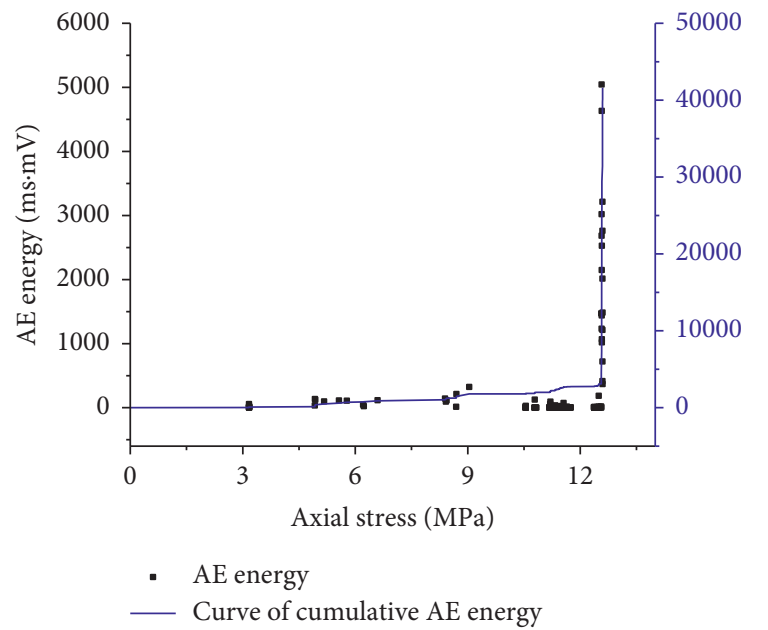

(f)

Figure 6: Relationship between stress and AE energy: (a) PC specimens; (b) PR specimens; (c) CR combined specimens with $\alpha=0^{\circ}$; (d) CR combined specimens with $\alpha=15^{\circ}$; (e) CR combined specimens with $\alpha=30^{\circ}$; (f) CR combined specimens with $\alpha=45^{\circ}$.

different structures are illustrated in Figure 6. PC, PR, and $\mathrm{CR}$ combined specimens all developed a small number of microfractures and also emitted low AE energies from the initial loading stage to that before peak axial stress. At peak axial stress, the cumulative $\mathrm{AE}$ energies in different specimens suddenly increased, and then the energies were 
synchronously released within a short time, thus exhibiting impact characteristics.

The impact-induced failure processes of different CR combined specimens are shown in Figure 7. The figure displays the impact-induced failure conditions at peak axial stress and final failure stage. Coal and rock sections in CR combined specimens with inclinations of $0^{\circ}$ and $15^{\circ} \mathrm{de}-$ veloped interconnected fractures at peak axial stress. In contrast, rock sections in CR combined specimens with inclinations of $30^{\circ}$ and $45^{\circ}$ did not undergo failure. The general level of damage of the CR combined specimens declined with increasing inclination.

\section{Failure Mechanism}

3.1. Stress and Failure Mechanism. To explore the accumulation and release of impact energy in the combined body, it is necessary to investigate the stress conditions causing the failure of the CR combined body. As shown in Figures 5(a) and 5(b), the stress-strain curves of PR specimens were quasilinear throughout the loading process. In contrast, although PC specimens were slightly compacted in the initial loading stage, the corresponding stress-strain curves in the middle and later loading stages were also quasilinear; therefore, when analysing the stress before the failure of CR combined specimens, the coal and rock sections were regarded as having a quasilinear constitutive relationship [31].

The stress on CR combined specimens is shown in Figure 8(a). The loading system applied axial stress $\sigma$ along the specimens, and then the stress was transferred to the coal section through the rock section. A coordinate system was established along the structural planes and the direction normal to the structural planes; the stress on coal section is shown in Figure 8(b) (where $\sigma_{x c}=\sigma \cos (\alpha)$ and $\left.\tau_{\mathrm{xyc}}=\sigma \cos (\alpha)\right)$. The deformation of each coal section was constrained by the rock section through structural planes under the constraint imposed by stress $\tau_{s}$, as shown in Figure $8(\mathrm{c})$. Before failure, the strain in the coal section was consistent with that in the rock section along the structural planes, so

$$
\varepsilon_{y c}=\varepsilon_{y \mathrm{r}},
$$

where $\varepsilon_{y c}$ and $\varepsilon_{y r}$ refer to strains on coal and rock section along the direction of the structural planes, respectively. According to elastic theory,

$$
\tau_{\mathrm{s}}=\frac{\sigma \cos (\alpha)\left(E_{\mathrm{c}} \mu_{\mathrm{r}}-E_{\mathrm{r}} \mu_{\mathrm{c}}\right)}{E_{\mathrm{c}} \mu_{\mathrm{r}}+E_{\mathrm{r}} \mu_{\mathrm{c}}-E_{\mathrm{c}}-E_{\mathrm{r}}},
$$

where $\mu_{c}$ and $\mu_{r}$ denote Poisson's ratios of coal and rock sections, respectively. Coal and rock sections were under three-dimensional stress states, and according to the Mohr-Coulomb strength criterion, the failure condition of the coal section is presented as follows:

$$
\sigma_{1 \mathrm{c}}=\xi_{\mathrm{c}} \sigma_{3 \mathrm{c}}+\sigma_{\mathrm{bc}},
$$

where $\sigma_{1 \mathrm{c}}$ denotes the maximum principal stress $(\mathrm{MPa})$ on the coal section in a CR combined specimen; $\xi_{c}$ represents the slope of the straight line of coal section based on the Mohr-Coulomb strength criterion; and $\sigma_{3 c}$ refers to the minimum principal stress $(\mathrm{MPa})$ on the coal section in $\mathrm{CR}$ combined specimens. Moreover, $\sigma_{1 \mathrm{c}}$ and $\sigma_{3 \mathrm{c}}$ could be calculated as follows:

$$
\left\{\begin{array}{l}
\sigma_{1 \mathrm{c}}=\frac{\sigma_{x \mathrm{c}}+\sigma_{y \mathrm{c}}}{2}+\sqrt{\left(\frac{\sigma_{x \mathrm{c}}-\sigma_{y c}}{2}\right)^{2}+\left(\tau_{x y c}\right)^{2}}, \\
\sigma_{3 \mathrm{c}}=\frac{\sigma_{x \mathrm{c}}+\sigma_{y c}}{2}-\sqrt{\left(\frac{\sigma_{x \mathrm{c}}-\sigma_{y c}}{2}\right)^{2}+\left(\tau_{x y c}\right)^{2}} .
\end{array}\right.
$$

By substituting material parameters in Table 1 into equations (8) and (9), the axial stress $\sigma$ required for failure of the coal section in $\mathrm{CR}$ combined specimens could be attained as follows:

$$
\sigma_{\mathrm{cr}-\mathrm{c}}=\frac{249.7}{2.957 \sqrt{100-81.11 \cos ^{2}(\alpha)}-5.411 \cos (\alpha)} .
$$

Similarly, the axial stress $\sigma$ required for the failure of a rock section was calculated as follows:

$$
\sigma_{\mathrm{cr}-\mathrm{r}}=\frac{938.2}{3.006 \sqrt{400-272.14 \cos ^{2}(\alpha)}-8.746 \cos (\alpha)}
$$

Owing to the axial stress $\left(\sigma_{\mathrm{cr}-\mathrm{c}}\right)$ triggering the failure of a coal section being lower than that $\left(\sigma_{\mathrm{cr}-\mathrm{r}}\right)$ leading to failure of the rock section, the theoretical strength of CR combined specimens was calculated by using equation (10).

3.2. Verification. The strength of CR combined specimens was predicted by using equation (10), and the predicted and measured values are listed in Table 5. To evaluate the error between predicted and measured values, the relative error was introduced:

$$
v=\frac{x-\mu_{x}}{\mu_{x}} \times 100 \%,
$$

where $v, x$, and $\mu_{x}$ denote the relative error between predicted and measured values, measured and predicted values, respectively. The relative error of various specimens was between -4.94 and 6.34, implying that the aforementioned stress analysis on CR combined specimens conformed to actual conditions. According to equation (10) and the measured result, it can be found that the strength of a CR combined body was mainly determined by the inclination of the structural planes; the larger the inclination, the lower the strength of the specimens.

\section{Calculation Model for Impact Energy}

4.1. Calculation Model. As shown in Figures 6(c) to 6(f), energy release occurred throughout the loading process of $\mathrm{CR}$ combined specimens, and microfractures were constantly generated, therein AE energy exhibited a high discreteness, which indicated that the microfracturing degree of specimens also showed a high discreteness. To quantify the 


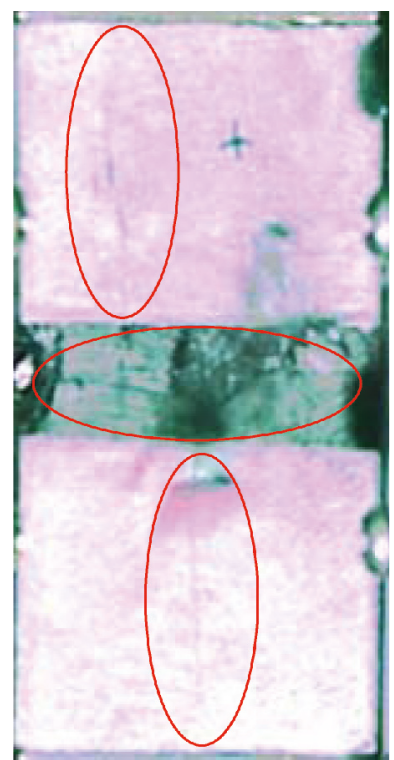

Peak stress

(a)

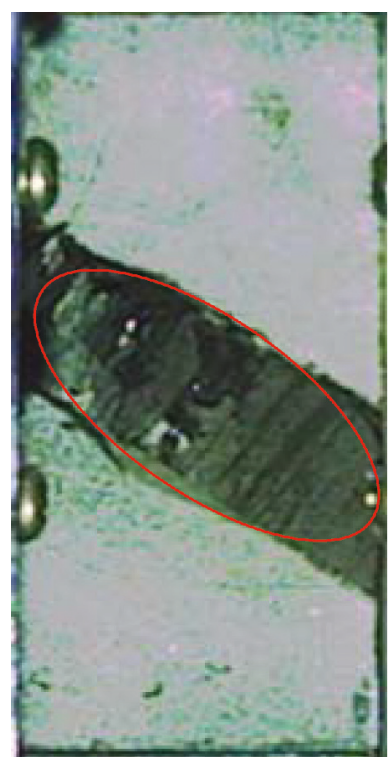

Peak stress

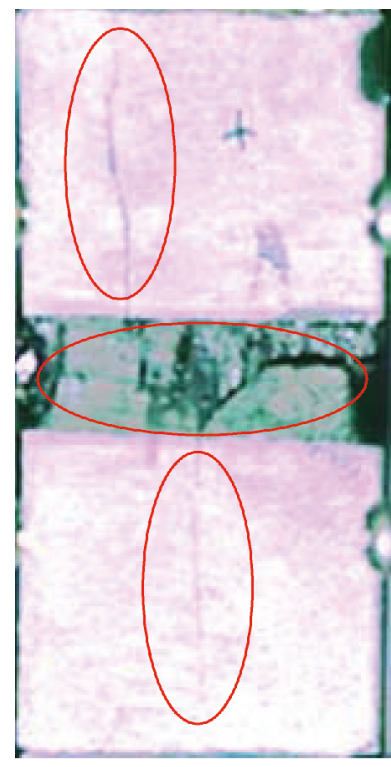

Final failure

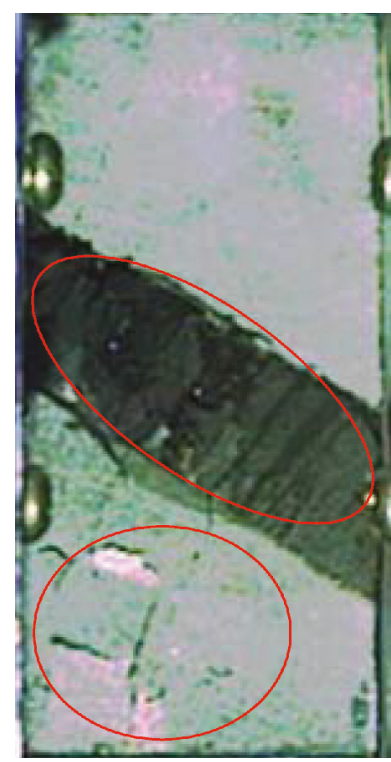

Final failure

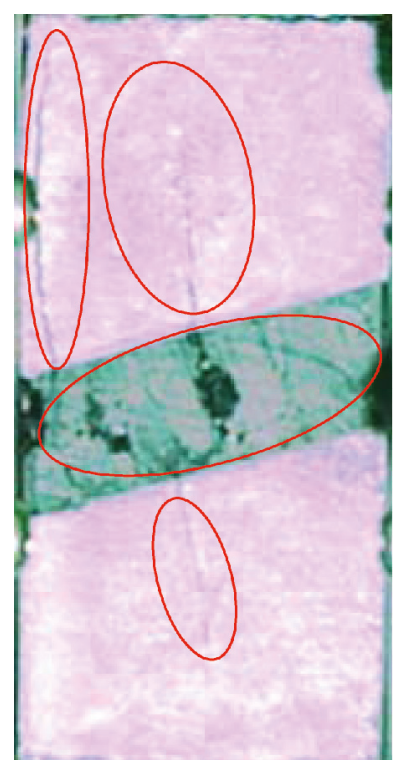

Peak stress



Peak stress



Final failure

(b)

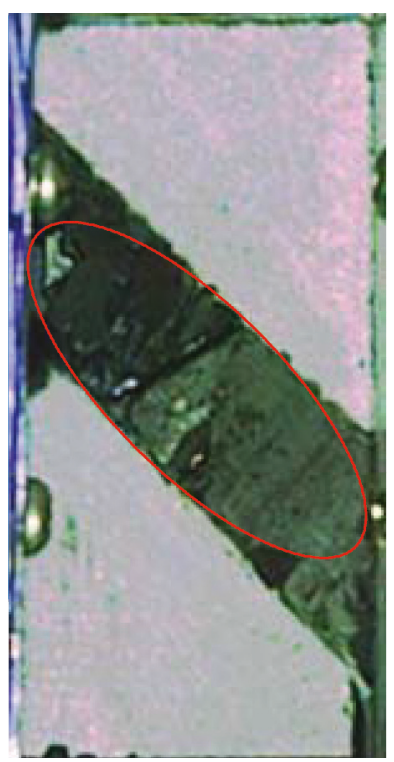

Final failure

(c)

(d)

FIgURE 7: Impact-induced failure process of CR combined specimens: (a) CR combined specimens with $\alpha=0^{\circ}$; (b) CR combined specimens with $\alpha=15^{\circ}$; (c) CR combined specimens with $\alpha=30^{\circ}$; (d) CR combined specimens with $\alpha=45^{\circ}$.

process of energy release in specimens, according to the theory of particle mechanics, it is supposed that the relationship between uniaxial strength $(\sigma)$ and volume density $(f(\sigma))$ of particulate elements of coal and rock masses is expressed as follows [32-34]:

$$
f(\sigma)=\lambda e^{-\lambda \sigma},
$$

where $\lambda$ represents the strength-volume rate parameter of particle elements. It is supposed that particle elements exhibited a linear-elastic constitutive relationship, and their energy density is expressed as follows [35]:

$$
e_{\mathrm{E}}=\frac{1}{2}\left(\sigma_{x} \varepsilon_{x}+\sigma_{y} \varepsilon_{y}+\sigma_{z} \varepsilon_{z}+\tau_{x y} \gamma_{x y}+\tau_{x z} \gamma_{x z}+\tau_{y z} \gamma_{y z}\right) \text {, }
$$

where $e_{E}$ denotes the energy density $(\mathrm{MPa})$ of particle elements. Before the impact-induced failure of CR combined specimens, with increasing load, cumulative energy released from coal or rock masses was governed by equation (15) on 


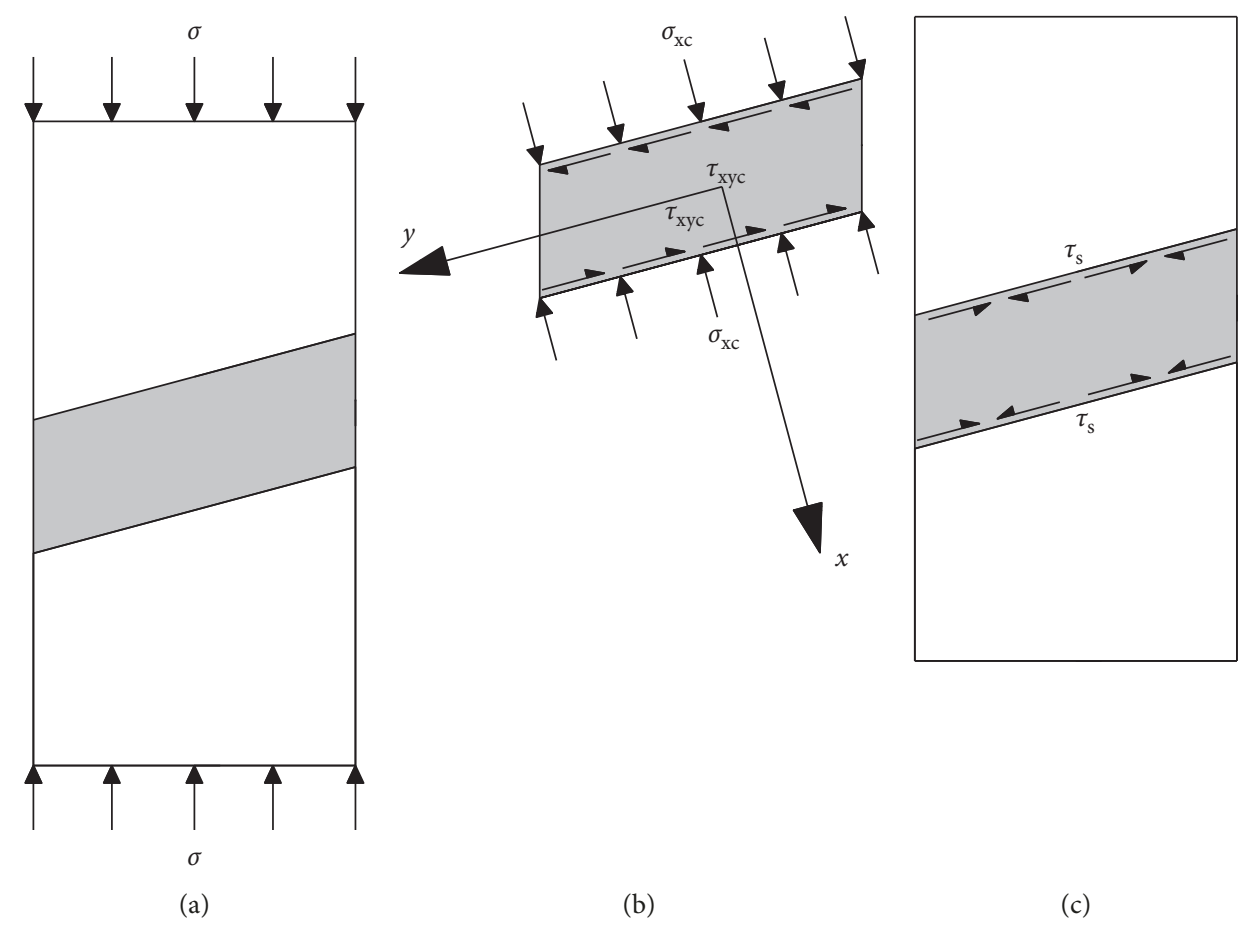

FIgURE 8: Stress analysis of specimens. Stress on (a) specimens and (b) coal section; (c) constraint force of coal section.

TABLE 5: Predicted strengths and measured strengths of CR combined specimens.

\begin{tabular}{|c|c|c|c|c|c|c|c|}
\hline $\begin{array}{l}\text { Serial number of } \\
\text { specimens }\end{array}$ & $\begin{array}{c}\text { Predicted } \\
\text { strength }(\mathrm{MPa})\end{array}$ & $\begin{array}{c}\text { Measured } \\
\text { strength }(\mathrm{MPa})\end{array}$ & $\begin{array}{l}\text { Relative } \\
\text { error }(\%)\end{array}$ & $\begin{array}{c}\text { Serial number of } \\
\text { specimens }\end{array}$ & $\begin{array}{c}\text { Predicted } \\
\text { strength }(\mathrm{MPa})\end{array}$ & $\begin{array}{c}\text { Measured } \\
\text { strength }(\mathrm{MPa})\end{array}$ & $\begin{array}{l}\text { Relative } \\
\text { error (\%) }\end{array}$ \\
\hline CR-0-1 & & 32.1103 & -4.21 & CR-30-1 & & 17.3016 & -4.94 \\
\hline CR-0-2 & 33.56 & 33.1421 & -1.13 & CR-30-2 & 18.07 & 19.3541 & 6.34 \\
\hline CR-0-3 & & 35.3115 & 5.34 & CR-30-3 & & 17.9453 & -1.4 \\
\hline Mean & & 33.5213 & & Mean & & 18.2003 & \\
\hline CR-15-1 & & 25.9652 & -2.91 & CR-45-1 & & 12.5735 & -3.69 \\
\hline CR-15-2 & 26.69 & 28.2658 & 5.69 & CR-45-2 & 13.16 & 13.6984 & 4.92 \\
\hline CR-15-3 & & 26.0026 & -2.77 & CR-45-3 & & 12.8954 & -1.23 \\
\hline Mean & & 26.7445 & & Mean & & 13.0558 & \\
\hline
\end{tabular}

condition that the particulate element with uniaxial strength of $\sigma$ was damaged:

$$
E^{\prime}=\int_{0}^{\sigma} e_{\mathrm{E}} V f(\sigma) \mathrm{d} \sigma
$$

where $E$ / represents the cumulative energy released $\left(10^{-3} \mathrm{~J}\right)$ from coal or rock masses before impact-induced failure and $V$ represents the volume $\left(\mathrm{mm}^{3}\right)$ of the coal or rock masses. By substituting equation (13) into equation (15), the cumulative energy release before impact-induced failure of coal and rock sections is as follows:

$$
E^{\prime}=\int_{0}^{\sigma} e_{\mathrm{E}} V \lambda e^{-\lambda \sigma} \mathrm{d} \sigma .
$$

When impact-induced failure of CR combined specimens occurred, the impact energy $\left(E_{b}\right)$ released from coal or rock masses was equivalent to the elastic energy accumulated in unbroken particle elements (with uniaxial strength larger than $\sigma_{b}$ ). Thus,

$$
E_{\mathrm{b}}=e_{\mathrm{E}} V\left(1-\int_{0}^{\sigma_{\mathrm{b}}} f\left(\sigma_{\mathrm{b}}\right) \mathrm{d} \sigma_{\mathrm{b}}\right)=e_{\mathrm{E}} V e^{-\lambda \sigma_{\mathrm{b}}}
$$

Hence, the calculation model for impact energy $\left(E_{\text {ber }}\right)$ in a CR combined body with inclinations of structural planes is expressed as follows:

$$
E_{\mathrm{bcr}}=e_{\mathrm{Ec}} V_{\mathrm{c}} e^{-\lambda_{\mathrm{c}} \sigma_{\mathrm{bc}}}+e_{\mathrm{Er}} V_{\mathrm{r}} e^{-\lambda_{\mathrm{r}} \sigma_{\mathrm{br}}},
$$

where $E_{\text {ber }}$ denotes the impact energy $\left(10^{-3} \mathrm{~J}\right)$ of the CR combined body with inclinations of structural planes, $e_{\mathrm{Ec}}$ and $e_{\mathrm{Er}}$ represent energy densities $(\mathrm{MPa}), V_{c}$ and $V_{r}$ represent the volumes $\left(\mathrm{mm}^{3}\right)$, while $\lambda_{c}$ and $\lambda_{r}$ denote the strength-volume rate parameters, of coal and rock masses, respectively, and $\sigma_{\mathrm{bc}}$ and $\sigma_{\mathrm{br}}$ denote the uniaxial strength $(\mathrm{MPa})$ of particle elements, of coal and rock masses, which were fractured immediately before impact-induced failure of the CR combined body, respectively. 


\subsection{Strength-Volume Rate Parameter}

4.2.1. AE Energy Conversion. AE energy $\left(E_{\mathrm{AE}}\right)$ reflects the fact that the energy $\left(E_{\mathrm{e}}\right)$ released during fracturing of specimens could be given by

$$
E_{\mathrm{AE}}=n E_{\mathrm{e}},
$$

where $E_{\mathrm{AE}}, n$, and $E_{\mathrm{e}}$ represent $\mathrm{AE}$ energy $(\mathrm{ms} \cdot \mathrm{mV}), \mathrm{AE}$ energy conversion coefficient $\left(\mathrm{ms} \cdot \mathrm{mV} / 10^{-3} \mathrm{~J}\right.$ ) and energy $\left(10^{-3} \mathrm{~J}\right)$ released from specimens, respectively. It can be seen from Figure 5(b) that, the stress-strain curve of PR specimens was approximately linear, and the energy $E_{\mathrm{e}}$ released from the PR specimens can be approximately equivalent to the elastic energy accumulated in the specimens. Thus, according to equation (14), the elastic energy accumulated in the PR specimens is expressed as follows:

$$
E_{\mathrm{e}}=\frac{V \sigma_{\mathrm{cr}}^{2}}{2 E_{\mathrm{r}}}
$$

Thus, the cumulative energy released from PR specimens during the entire loading process was calculated by using equation (20). The cumulative energy $\left(E_{\mathrm{e}}\right)$ released from of different rock specimens and corresponding cumulative $\mathrm{AE}$ energy $\left(E_{\mathrm{AE}}\right)$ are listed in Table 6 . Through calculation (equation (19), the AE energy conversion coefficient $(n)$ of different $\mathrm{PR}$ specimens ranged from 13.435 to $14.249 \mathrm{~ms} \cdot \mathrm{mV} / 10^{-3} \mathrm{~J}$, and its mean $\left(13.796 \mathrm{~ms} \cdot \mathrm{mV} / 10^{-3} \mathrm{~J}\right)$ was used as the conversion coefficient here.

4.2.2. Strength-Volume Density Constant of Coal and Rock. In accordance with equation (16), the cumulative energy releases $E_{\mathrm{c}}^{\prime}$ and $E_{\mathrm{r}}^{\prime}$ of PC and PR specimens before impactinduced failure were separately calculated as follows:

$$
\begin{aligned}
& E_{\mathrm{c}}^{\prime}=\int_{0}^{\sigma} e_{\mathrm{Ec}} V \lambda_{\mathrm{c}} e^{-\lambda_{\mathrm{c}} \sigma} \mathrm{d} \sigma, \\
& E_{\mathrm{r}}^{\prime}=\int_{0}^{\sigma} e_{\mathrm{Er}} V \lambda_{\mathrm{r}} e^{-\lambda_{\mathrm{r}} \sigma} \mathrm{d} \sigma .
\end{aligned}
$$

According to equation (19), the cumulative AE energies of PC and PR specimens before impact-induced failure were separately obtained as follows:

$$
\begin{aligned}
& E_{\mathrm{c}-\mathrm{AE}}^{\prime}=n \int_{0}^{\sigma} e_{\mathrm{Ec}} V \lambda_{\mathrm{c}} e^{-\lambda_{\mathrm{c}} \sigma} \mathrm{d} \sigma, \\
& E_{\mathrm{r}-\mathrm{AE}}^{\prime}=n \int_{0}^{\sigma} e_{\mathrm{Er}} V \lambda_{\mathrm{r}} e^{-\lambda_{\mathrm{r}} \sigma} \mathrm{d} \sigma .
\end{aligned}
$$

Under uniaxial loading, PC and PR specimens were only subjected to axial load. Based on equation (14), the energy
TABLE 6: Cumulative energy during the entire loading process and conversion coefficient.

\begin{tabular}{lccc}
\hline $\begin{array}{l}\text { Serial number of } \\
\text { specimens }\end{array}$ & $\begin{array}{c}E_{\mathrm{AE}} \\
(\mathrm{ms} \cdot \mathrm{mV})\end{array}$ & $\begin{array}{c}E_{\mathrm{e}} \\
\left(10^{-3} \mathrm{~J}\right)\end{array}$ & $\begin{array}{c}n(\mathrm{~ms} \cdot \mathrm{mV} / \\
\left.10^{-3} \mathrm{~J}\right)\end{array}$ \\
\hline PR-1 & 316279 & 23541.2 & 13.4351 \\
PR-2 & 303657 & 22157.1 & 13.7047 \\
PR-3 & 327701 & 22998.7 & 14.2487 \\
Mean & & & 13.7962 \\
\hline
\end{tabular}

densities of PC and PR specimens were separately shown as follows:

$$
\begin{aligned}
& e_{\mathrm{Ec}}=\frac{\sigma^{2}}{2 E}, \\
& e_{\mathrm{Er}}=\frac{\sigma^{2}}{2 E} .
\end{aligned}
$$

By separately fitting the curves of cumulative AE energies in PC and PR specimens before impact-induced failure by using equations (23) and (24), the strength-volume rate parameter $\lambda_{c}$ and $\lambda_{r}$ of coal and rock masses could be attained. The impact energies in specimens were equivalent to the energy released by all particle elements with uniaxial strength greater than $\sigma$, which is beyond the range of datafitting adopted here. Owing to dynamic failure times of different specimens all being less than $200 \mathrm{~ms}$, the fitting data range was deemed to be from the beginning of loading to $200 \mathrm{~ms}$ before reaching the peak stress. The fitting curves are shown in Figure 9.

The fitting results of different specimens are listed in Table 7: $R^{2}$ for data from PC and PR specimens was between 0.94365 and 0.97692 , and equations (21) and (22) can accurately describe the process of energy release of specimens before impact-induced failure. The strength-volume rate parameters $\lambda_{c}$ and $\lambda_{r}$ of coal and rock masses were separately valued as their corresponding means $(0.02557$ and 0.00156).

\subsection{Prediction of Cumulative AE Energies before Impact- Induced Failure}

4.3.1. Fracturing Conditions and Energy Density of Particle Elements in CR Combined Specimens. Based on the analysis presented in Section 3, coal and rock sections in CR combined specimens are under plane stress. Based on equations (6) (9), the failure condition of particle elements of coal sections with strength $\sigma_{\mathrm{bc}}$ in CR combined specimens is as follows:

$$
\sigma_{\mathrm{bc}}(\sigma)=\left[\frac{\left(\xi_{\mathrm{c}}+1\right) \cos (\alpha) \sqrt{4+\left(m^{2}-2 m-3\right)}-\cos (\alpha)\left(\xi_{\mathrm{c}}-1\right)(m+1)}{2}\right] \sigma
$$




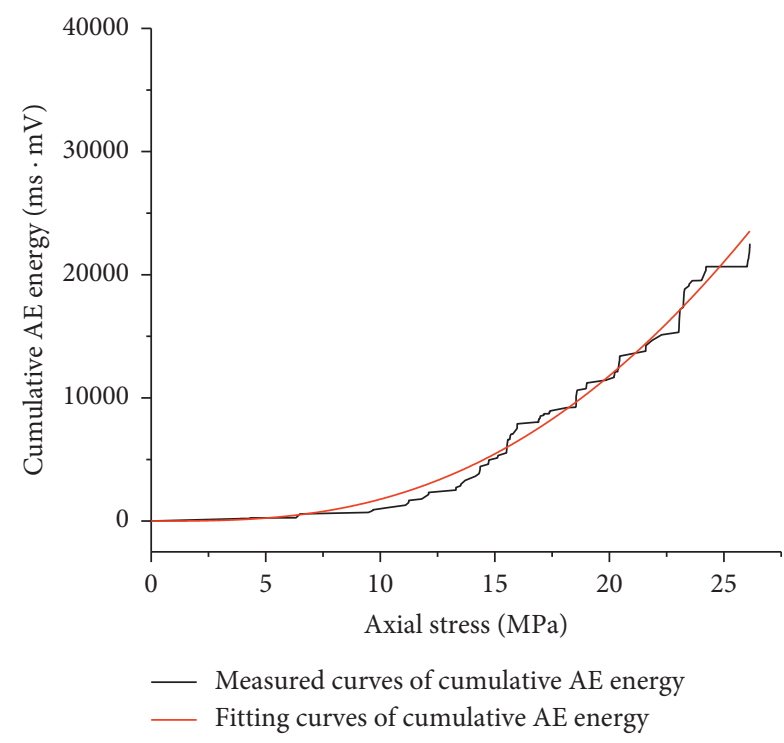

(a)



(b)

FIGURE 9: Fitting curves of cumulative AE energies in coal and rock masses before impact-induced failure: (a) PC specimens; (b) PR specimens.

TABLE 7: Fitting results of cumulative AE energies in coal and rock masses.

\begin{tabular}{lcccr}
\hline Serial number of specimens & $\lambda_{c}$ & $R^{2}$ & Serial number of specimens & $\lambda_{r}$ \\
\hline PC-1 & 0.02495 & 0.97841 & PR-1 & 0.00158 \\
PC-2 & 0.02671 & 0.97105 & PR-2 & 0.94062 \\
PC-3 & 0.02506 & 0.95187 & PR-3 & 0.00149 \\
Mean & 0.02557 & 0.96711 & Mean & 0.00161 \\
\hline
\end{tabular}

The failure condition of particle elements of rock sections with strength $\sigma_{\mathrm{br}}$ was obtained as follows:

$$
\sigma_{\mathrm{br}}(\sigma)=\left[\frac{\left(\xi_{r}+1\right) \cos (\alpha) \sqrt{4+\left(m^{2}+2 m-3\right)}+\cos (\alpha)\left(\xi_{r}-1\right)(m-1)}{2}\right] \sigma
$$

where $m=\left(E_{\mathrm{c}} \mu_{\mathrm{r}}-E_{\mathrm{r}} \mu_{\mathrm{c}}\right) /\left(E_{\mathrm{c}} \mu_{\mathrm{r}}+E_{\mathrm{r}} \mu_{\mathrm{c}}-E_{\mathrm{c}}-E_{\mathrm{r}}\right)$. Equations (28) and (29) separately show the energy densities $e_{\mathrm{Ec}}$ and $e_{\mathrm{Er}}$ of particle elements in coal and rock sections within CR combined specimens:

$$
\begin{aligned}
& e_{\mathrm{Ec}}(\sigma)=\frac{2+2 \mu_{\mathrm{c}}-\cos ^{2}(\alpha)\left[2 \mu_{\mathrm{c}}(m+1)^{2}-2 m^{2}+1\right]}{2 E_{\mathrm{c}}} \sigma^{2}, \\
& e_{\mathrm{Er}}(\sigma)=\frac{2+2 \mu_{\mathrm{r}}-\cos ^{2}(\alpha)\left[2 \mu_{\mathrm{r}}(m-1)^{2}-2 m^{2}+1\right]}{2 E_{\mathrm{r}}} \sigma^{2} .
\end{aligned}
$$

4.3.2. Cumulative Energy before Impact-Induced Failure. The cumulative energy releases from coal and rock section in CR combined specimens with inclinations of structural planes before impact-induced failure are separately expressed as follows:

$$
\begin{aligned}
& E_{\mathrm{c}}^{\prime}=\int_{0}^{\sigma_{\mathrm{bc}}} e_{\mathrm{Ec}} V_{\mathrm{c}} \lambda_{\mathrm{c}} e^{-\lambda_{\mathrm{c}} \sigma_{\mathrm{bc}}} \mathrm{d} \sigma_{\mathrm{bc}} \\
& E_{\mathrm{r}}^{\prime}=\int_{0}^{\sigma_{\mathrm{br}}} e_{\mathrm{Er}} V_{\mathrm{r}} \lambda_{\mathrm{r}} e^{-\lambda_{\mathrm{r}} \sigma_{\mathrm{br}}} \mathrm{d} \sigma_{\mathrm{br}}
\end{aligned}
$$

The cumulative energy release $\left(E_{\mathrm{cr}}^{\prime}\right)$ before impact-induced failure of CR combined specimens with different inclinations is the energy jointly released from coal and rock specimens, so the following equation could be obtained as follows:

$$
E_{\mathrm{cr}}^{\prime}=E_{\mathrm{c}}^{\prime}+E_{\mathrm{r}}^{\prime}
$$

According to equation (19), the corresponding cumulative $\mathrm{AE}$ energy $\left(E_{\mathrm{cr}-\mathrm{AE}}^{\prime}\right)$ before impact is given by: 




(a)



(c)

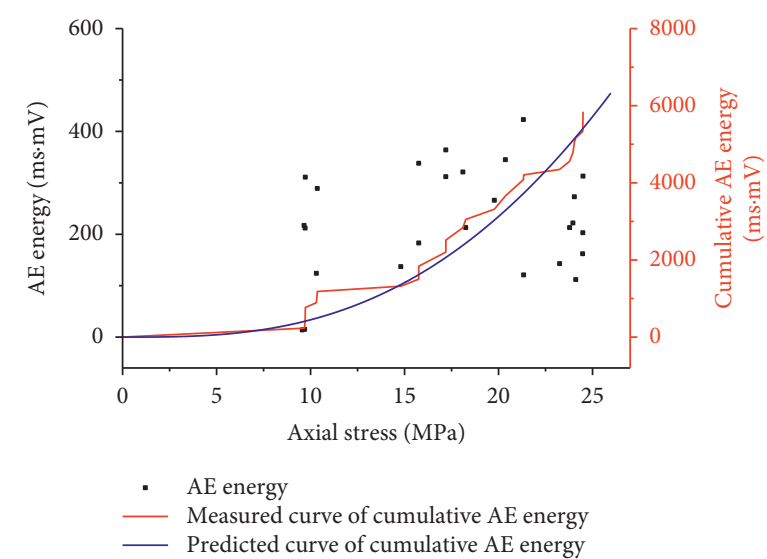

(b)



(d)

Figure 10: Curves of cumulative AE energies before failure of CR combined specimens (a) with $\alpha=0^{\circ}$; (b) $\alpha=15^{\circ}$; (c) $\alpha=30^{\circ}$; (d) $\alpha=45^{\circ}$.

$$
E_{\mathrm{cr}-\mathrm{AE}}^{\prime}=n\left(E_{\mathrm{c}}^{\prime}+E_{\mathrm{r}}^{\prime}\right)
$$

Parameters pertaining to the mechanical properties of coal and rock masses in Table 1, the strength-volume density constant in Table 7 , and equations (27) (33) were substituted into equations (30) and (31), and AE energy conversion coefficient $n=13.7962$ was substituted into equation (32). Based thereon, the predicted curves of cumulative AE energy before impact-induced failure of $\mathrm{CR}$ combined specimens with different inclinations of structural planes can be obtained. The measured values of AE energies and measured and predicted curves of cumulative AE energies before impact-induced failure of CR combined specimens with different inclinations of structural planes are summarised in Figure 10. The AE energy exhibited a high discreteness, while the curve of cumulative AE energy showed strong regularity and was consistent with the predicted curve. The cumulative AE energies before impactinduced failure of CR combined specimens with different inclinations of structural planes were predicted, and the data were compared with the measured value (Table 8), with a relative error between -7.6 and 7.6 .

4.4. Prediction of Impact Energy. In accordance with equations (6) (9), when CR combined specimens were damaged, the minimum strengths of unfractured particle elements of coal and rock sections are separately given by

$$
\begin{aligned}
& \sigma_{\mathrm{bc}}=\left[\frac{\left(\xi_{\mathrm{c}}+1\right) \cos (\alpha) \sqrt{4+\left(m^{2}-2 m-3\right)}-\cos (\alpha)\left(\xi_{\mathrm{c}}-1\right)(m+1)}{2}\right] \sigma_{\mathrm{cr}}, \\
& \sigma_{\mathrm{br}}=\left[\frac{\left(\xi_{\mathrm{r}}+1\right) \cos (\alpha) \sqrt{4+\left(m^{2}+2 m-3\right)}+\cos (\alpha)\left(\xi_{\mathrm{r}}-1\right)(m-1)}{2}\right] \sigma_{\mathrm{cr}} .
\end{aligned}
$$


TABLE 8: Cumulative AE energy before failure of CR combined specimens.

\begin{tabular}{|c|c|c|c|}
\hline $\begin{array}{l}\text { Serial number of } \\
\text { specimens }\end{array}$ & $\begin{array}{l}\text { Predicted cumulative AE energy before impact- } \\
\text { induced failure }(\mathrm{ms} \cdot \mathrm{mV})\end{array}$ & $\begin{array}{l}\text { Measured cumulative AE energy before impact- } \\
\text { induced failure }(\mathrm{ms} \cdot \mathrm{mV})\end{array}$ & $\begin{array}{c}\text { Relative } \\
\text { error }\end{array}$ \\
\hline CR-0-1 & 8677 & 8875 & 2.3 \\
\hline CR-0-2 & 9444 & 9036 & -4.3 \\
\hline CR-0-3 & 11181 & 10936 & -2.2 \\
\hline Mean & 9735 & 9616 & \\
\hline CR-15-1 & 6324 & 5846 & -7.6 \\
\hline CR-15-2 & 7917 & 7425 & -6.2 \\
\hline CR-15-3 & 6348 & 6532 & 2.9 \\
\hline Mean & 6840 & 6601 & \\
\hline CR-30-1 & 3730 & 3801 & 1.9 \\
\hline CR-30-2 & 5003 & 4832 & -3.4 \\
\hline CR-30-3 & 4106 & 4026 & -1.9 \\
\hline Mean & 4261 & 4220 & \\
\hline CR-45-1 & 2980 & 2871 & -3.7 \\
\hline CR-45-2 & 3723 & 3611 & -3 \\
\hline CR-45-3 & 3183 & 3425 & 7.6 \\
\hline Mean & 3287 & 3302 & \\
\hline
\end{tabular}

TABLE 9: Measured values of AE impact energy in specimens and their relative errors.

\begin{tabular}{|c|c|c|c|c|c|c|c|}
\hline $\begin{array}{l}\text { Serial number } \\
\text { of specimens }\end{array}$ & $\begin{array}{c}\text { Predicted AE } \\
\text { impact energy } \\
(\mathrm{ms} \cdot \mathrm{mV})\end{array}$ & $\begin{array}{c}\text { Measured AE } \\
\text { impact energy } \\
(\mathrm{ms} \cdot \mathrm{mV})\end{array}$ & $\begin{array}{l}\text { Relative } \\
\text { error (\%) }\end{array}$ & $\begin{array}{l}\text { Serial number } \\
\text { of specimens }\end{array}$ & $\begin{array}{c}\text { Predicted AE } \\
\text { impact energy } \\
(\mathrm{ms} \cdot \mathrm{mV})\end{array}$ & $\begin{array}{c}\text { Measured AE } \\
\text { impact energy } \\
(\mathrm{ms} \cdot \mathrm{mV})\end{array}$ & $\begin{array}{l}\text { Relative } \\
\text { error (\%) }\end{array}$ \\
\hline CR-0-1 & 149120 & 143014 & -4.1 & CR-30-1 & 59406 & 59104 & -0.5 \\
\hline CR-0-2 & 158076 & 149484 & -5.4 & CR-30-2 & 72918 & 67522 & -7.4 \\
\hline CR-0-3 & 177639 & 161884 & -8.9 & CR-30-3 & 63519 & 61232 & -3.6 \\
\hline Mean & 161612 & 151461 & & Mean & 65281 & 62619 & \\
\hline CR-15-1 & 108598 & 105713 & -2.7 & CR-45-1 & 39346 & 38733 & -1.6 \\
\hline CR-15-2 & 126963 & 123693 & -2.6 & CR-45-2 & 45893 & 43654 & -4.9 \\
\hline CR-15-3 & 108887 & 114063 & 4.8 & CR-45-3 & 41178 & 38940 & -5.4 \\
\hline Mean & 114816 & 114490 & & Mean & 42139 & 40442 & \\
\hline
\end{tabular}

The cumulative elastic energy densities in unfractured particle elements in coal and rock sections separately are given by

$$
\begin{gathered}
e_{\mathrm{Ec}}=\frac{2+2 \mu_{\mathrm{c}}-\cos ^{2}(\alpha)\left[2 \mu_{\mathrm{c}}(m+1)^{2}-2 m^{2}+1\right]}{2 E_{\mathrm{c}}} \sigma_{\mathrm{cr}}^{2} \\
e_{\mathrm{Er}}=\frac{2+2 \mu_{\mathrm{r}}-\cos ^{2}(\alpha)\left[2 \mu_{\mathrm{r}}(m-1)^{2}-2 m^{2}+1\right]}{2 E_{\mathrm{r}}} \sigma_{\mathrm{cr}}^{2}
\end{gathered}
$$

The AE impact energy $E_{\mathrm{bcr}-\mathrm{AE}}$ of $\mathrm{CR}$ combined specimens could be predicted by using the following equation

$$
E_{\mathrm{bcr}-\mathrm{AE}}=n\left(e_{\mathrm{Ec}} V_{\mathrm{c}} e^{-\lambda_{\mathrm{c}} \sigma_{\mathrm{bc}}}+e_{\mathrm{Er}} V_{\mathrm{r}} e^{-\lambda_{\mathrm{r}} \sigma_{\mathrm{br}}}\right)
$$

By substituting equations (34) (37) into (38), the predicted value of $\mathrm{AE}$ impact energy in $\mathrm{CR}$ combined specimens was obtained. The measured value of AE impact energy was equivalent to the cumulative AE energy within
$200 \mathrm{~ms}$ before, and after, reaching peak stress. As shown in Table 9, compared with the predicted value, the relative error of the measured values of AE impact energies in different CR combined specimens ranged from -8.9 to 4.8 . With increasing inclination, the impact energy in CR combined specimens decreased.

4.5. Analysis on Effects of Inclination on Impact Energy in a CR Combined Body. According to equations (34) and (35), when the inclination $\alpha$ was large, particle elements were easily fractured, which led to a small volume density of unfractured particle elements when the CR combined body was damaged. In addition, in accordance with equations (36) and (37), the energy density of particle elements in the CR combined body showed a quadratic positive correlation with the strength $\sigma_{\mathrm{cr}}$ of a CR combined body when failure occurred. Based on equations (10), the strength $\sigma_{\text {cr }}$ decreased with the increase of inclination $\alpha$. Therefore, the greater the inclination, the lower the strength of the CR combined body and the smaller the volume density and energy density of unfractured particle elements at failure. This results in 
less impact energy being released when the CR combined body was damaged.

\section{Conclusions}

The mechanical properties of a CR combined body with different inclinations of its structural planes were tested, and its failure mechanism was analysed. On this basis, a calculation model for impact energy in a CR combined body was proposed, and its rationality was validated by using data from AE monitoring. The following conclusions could be drawn:

(1) Inclination significantly affected the mechanical properties of a CR combined body. With increasing inclination, the axial elastic modulus and Poisson's ratio of rock section in a CR combined body increased, while the axial elastic modulus of such coal samples decreased.

(2) Compared with rock burst-prone coal and rock masses, a CR combined body also showed significant impact-induced failure characteristics. With increasing inclination, the failure mode of a CR combined body varied from one of overall failure to failure of only the coal samples. Therefore, the level of damage to specimens decreased.

(3) The calculation model for impact energy in a CR combined body with different inclinations of structural planes is given by $E_{\mathrm{bcr}}=e_{\mathrm{Ec}} V_{\mathrm{c}} e^{-\lambda_{\mathrm{c}} \sigma_{\mathrm{bc}}}+$ $e_{\mathrm{Er}} V_{\mathrm{r}} e^{-\lambda_{\mathrm{r}} \sigma_{\mathrm{br}}}$. Inclination exerted a significant influence on the impact energy in a CR combined body, that is, the greater the inclination, the lower the impact energy in the CR combined body.

\section{Abbreviations}

$\delta: \quad$ Thickness of a coal section, $\mathrm{mm}$

$\alpha: \quad$ Inclination of a coal section,

$\sigma: \quad$ Axial stress on a specimen, $\mathrm{MPa}$

$P$ : $\quad$ Load on a specimen, $\mathrm{N}$

$S$ : $\quad$ Cross-sectional area of a specimen, $\mathrm{mm}^{2}$

$\varepsilon_{\mathrm{c}}: \quad$ Axial strain in a coal section, numeric

$\Delta l$ : Amount of axial deformation of a CR combined specimen, $\mathrm{mm}$

$\varepsilon_{\mathrm{r}}: \quad$ Axial strain in the rock, numeric

$l_{\mathrm{c}}: \quad$ Axial height of the coal section, $\mathrm{mm}$

$l_{\mathrm{r}}: \quad$ Axial height of the rock, $\mathrm{mm}$

$E_{\mathrm{AE}}$ : Cumulative $\mathrm{AE}$ energy in a specimen during the entire loading process, $\mathrm{ms} \cdot \mathrm{mV}$

$e_{\mathrm{AE} i}: \quad$ AE energy of a single fracture event, $\mathrm{ms} \cdot \mathrm{mV}$

$\sigma_{\mathrm{cr}}: \quad$ Strength of the specimen, $\mathrm{MPa}$

$V_{\sigma i}: \quad$ Coefficient of standard deviation of the strength of specimen, numeric

$\frac{\sigma_{\mathrm{cr}}:}{\sigma_{\mathrm{cr}}}: \quad \begin{aligned} & \text { Strength of the } i^{\text {th }} \text { specimen, } \mathrm{MPa} \\ & \text { Mean average strength of a group of specimens, }\end{aligned}$ $\mathrm{MPa}$
Coefficient of standard deviation of cumulative AE energy, numeric

$E_{\mathrm{AE} i}$ : Cumulative AE energy of the $i^{\text {th }}$ channel during the entire loading process, $\mathrm{ms} \cdot \mathrm{mV}$

$\overline{E_{\mathrm{AE}}}$ : Mean cumulative AE energy of the specimen on all channels, $\mathrm{ms} \cdot \mathrm{mV}$

$\sigma_{x \mathrm{c}}$ : Positive stress on a coal section in the $x$-direction, $\mathrm{MPa}$

$\tau_{x y c}: \quad$ Shear stress on a coal section in the $x$-direction, $\mathrm{MPa}$

$\tau_{s}: \quad$ Shear stress on a CR structural plane, $\mathrm{MPa}$

$\varepsilon_{y c}$ : Strain on a coal section along the direction of the structural plane, numeric

$\varepsilon_{y \mathrm{r}}$ : Strain on a rock section along the direction of the structural plane, numeric

$\mu_{\mathrm{c}}$ : Poisson's ratio of a coal section, numeric

$\mu_{\mathrm{r}}: \quad$ Poisson's ratio of a rock section, numeric

$\sigma_{1 \mathrm{c}}: \quad$ Maximum principal stress on the coal section in a CR combined specimen, $\mathrm{MPa}$

$\sigma_{3 \mathrm{c}}: \quad$ Minimum principal stress on the coal section in CR combined specimen, $\mathrm{MPa}$

$\xi_{c}$ : $\quad$ Slope of the straight line of coal section based on the Mohr-Coulomb strength criterion, numeric

$\sigma_{\text {cr-c }}: \quad$ Axial stress $\sigma$ required for failure of the coal section in a CR combined specimen, $\mathrm{MPa}$

$\sigma_{\mathrm{cr}-\mathrm{r}}: \quad$ Axial stress $\sigma$ required for the failure of a rock section in a CR combined specimen, $\mathrm{MPa}$

$v$ : $\quad$ Relative error between predicted and measured values, numeric

$x$ : $\quad$ Measured value of strength of a CR combined specimen, $\mathrm{MPa}$

$\mu_{x}$ : $\quad$ Predicted value of strength of a CR combined specimen, $\mathrm{MPa}$

$\lambda$ : $\quad$ Strength-volume rate parameter of particle elements, numeric

$e_{\mathrm{E}}: \quad$ Energy density of particle elements, $\mathrm{MPa}$

$E^{\prime}$ : Cumulative energy before impact-induced failure, $10^{-3} \mathrm{~J}$

$V: \quad$ Volume of the coal or rock masses, $\mathrm{mm}^{3}$

$E_{\mathrm{b}}$ : $\quad$ Impact energy of the coal or rock mass, $10^{-3} \mathrm{~J}$

$\sigma_{\mathrm{b}}$ : $\quad$ Minimum strength of unfractured particle elements in coal and rock sections when CR combined specimens are damaged, $\mathrm{MPa}$

$E_{\mathrm{bcr}}$ : Impact energy in a CR combined body with inclinations of structural planes, $10^{-3} \mathrm{~J}$

$e_{\mathrm{Ec}}$ : Energy density of a particulate element in a coal mass, $\mathrm{MPa}$

$e_{\mathrm{Er}}$ : $\quad$ Energy density of a particulate element in a rock mass, $\mathrm{MPa}$

$V_{c}$ : $\quad$ Volume of a coal section in a CR combined specimen, $\mathrm{mm}^{3}$

$V_{\mathrm{r}}$ : $\quad$ Volume of a rock section in a CR combined specimen, $\mathrm{mm}^{3}$

$\lambda_{c}$ : $\quad$ Strength-volume rate a parameter of coal mass, numeric

$\lambda_{\mathrm{r}}$ : Strength-volume rate a parameter of rock mass, numeric 

$\sigma_{\mathrm{bc}}: \quad$ Uniaxial strength of a particle element of coal mass, $\mathrm{MPa}$
$\sigma_{\mathrm{br}}$ : Uniaxial strength of a particle element of rock mass, $\mathrm{MPa}$
$E_{\mathrm{e}}$ : $\quad$ Eenergy released from a specimen during the entire loading process, $10^{-3} \mathrm{~J}$
$n$ : $\quad$ AE energy conversion coefficient of $E_{\mathrm{AE}}$ and $E_{e}$, $\mathrm{ms} \cdot \mathrm{mV} / 10^{-3} \mathrm{~J}$
$E_{\mathrm{c}}^{\prime}$ : $\quad$ Cumulative energy in a PC specimen before impact-induced failure, $10^{-3} \mathrm{~J}$
$E_{\mathrm{r}}^{\prime}$ : $\quad$ Cumulative energy in a PR specimen before impact-induced failure, $10^{-3} \mathrm{~J}$
$E_{\mathrm{cr}}^{\prime}$ : Cumulative energy in a CR combined specimen before impact-induced failure, $10^{-3} \mathrm{~J}$
$R^{2}: \quad$ Goodness of fit, numeric
$E_{\mathrm{bcr}-\mathrm{AE}}$ : AE impact energy inf a CR combined specimen, $\mathrm{ms} \cdot \mathrm{mV}$.

\section{Data Availability}

Some of the data used to support the findings of this study are included within the article, and the other parts of the data used to support the findings of this study are available from the corresponding author upon request.

\section{Conflicts of Interest}

The authors declare that there are no conflicts of interest regarding the publication of this paper.

\section{Acknowledgments}

The authors acknowledge the financial support provided by the Ordinary University Graduate Student Scientific Research Innovation Projects of Jiangsu Province (no. KYLX16_0557) and the National Natural Science Foundation Project of China (grant no. 51564044).

\section{References}

[1] M. C. He, J. L. Miao, and J. L. Feng, "Rock burst process of limestone and its acoustic emission characteristics under truetriaxial unloading conditions," International Journal of Rock Mechanics and Mining Sciences, vol. 47, no. 2, pp. 286-298, 2010.

[2] J.-c. Wang, F.-x. Jiang, X.-j. Meng, X.-y. Wang, S.-t. Zhu, and Y. Feng, "Mechanism of rock burst occurrence in specially thick coal seam with rock parting," Rock Mechanics and Rock Engineering, vol. 49, no. 5, pp. 1953-1965, 2016.

[3] X. Li, E. Wang, Z. Li, Z. Liu, D. Song, and L. Qiu, "Rock burst monitoring by integrated microseismic and electromagnetic radiation methods," Rock Mechanics and Rock Engineering, vol. 49, no. 11, pp. 4393-4406, 2016.

[4] W. Cai, L. Dou, S. Gong, Z. Li, and S. Yuan, "Quantitative analysis of seismic velocity tomography in rock burst hazard assessment," Natural Hazards, vol. 75, no. 3, pp. 2453-2465, 2015.

[5] Z. H. Ouyang, Q. X. Qi, S. K. Zhao, B. Y. Wu, and N. B. Zhang, "The mechanism and application of deep-hole precracking blasting on rockburst prevention," Shock and Vibration, vol. 2015, p. 7, 2015.
[6] J. Liu, E. Wang, D. Song, S. Wang, and Y. Niu, "Effect of rock strength on failure mode and mechanical behavior of composite samples," Arabian Journal of Geosciences, vol. 8, no. 7, pp. 4527-4539, 2015.

[7] K. Wang and F. Du, "Experimental investigation on mechanical behavior and permeability evolution in coal-rock combined body under unloading conditions," Arabian Journal of Geosciences, vol. 12, no. 14, p. 15, 2019.

[8] F. Du, K. Wang, G. Wang, Y. Jiang, C. Xin, and X. Zhang, "Investigation of the acoustic emission characteristics during deformation and failure of gas-bearing coal-rock combined bodies," Journal of Loss Prevention in the Process Industries, vol. 55, pp. 253-266, 2018.

[9] X. S. Liu, Y. L. Tan, J. G. Ning, Y. W. Lu, and Q. H. Gu, "Mechanical properties and damage constitutive model of coal in coal-rock combined body," International Journal of Rock Mechanics And Mining Sciences, vol. 110, pp. 140-150, 2018.

[10] B. Huang and J. Liu, "The effect of loading rate on the behavior of samples composed of coal and rock," International Journal Of Rock Mechanics And Mining Sciences, vol. 61, pp. 23-30, 2013.

[11] D. M. Guo, J. P. Zuo, Y. Zhang, and R. S. Yang, "Research on strength and failure mechanism of deep coal-rock combination bodies of different inclined angles," Rock and Soil Mechanics, vol. 32, no. 5, pp. 1333-1339, 2011.

[12] T. Wiens, "Engine speed reduction for hydraulic machinery using predictive algorithms," International Journal of Hydromechatronics, vol. 2, no. 1, pp. 16-31, 2019.

[13] M. Cinefra, "Numerical method for frequency response in visco-embedded nanoplate," International Journal of Hydromechatronics, vol. 2, no. 2, pp. 119-130, 2019.

[14] T. Wen, H. Tang, J. Ma, and Y. Liu, "Energy analysis of the deformation and failure process of sandstone and damage constitutive model," KSCE Journal of Civil Engineering, vol. 23, no. 2, pp. 513-524, 2019.

[15] X.-p. Zhang, Q. Zhang, and S. Wu, "Acoustic emission characteristics of the rock-like material containing a single flaw under different compressive loading rates," Computers and Geotechnics, vol. 83, pp. 83-97, 2017.

[16] S.-Q. Yang, P. G. Ranjith, H.-W. Jing, W.-L. Tian, and Y. Ju, "An experimental investigation on thermal damage and failure mechanical behavior of granite after exposure to different high temperature treatments," Geothermics, vol. 65, pp. 180-197, 2017.

[17] D. Yin, S. Chen, X. Liu, and H. Ma, "Effect of joint angle in coal on failure mechanical behaviour of roof rock-coal combined body," Quarterly Journal of Engineering Geology and Hydrogeology, vol. 51, no. 2, pp. 202-209, 2018.

[18] Y. Chen, J. Zuo, D. Liu, and Z. Wang, "Deformation failure characteristics of coal-rock combined body under uniaxial compression: experimental and numerical investigations," Bulletin of Engineering Geology and the Environment, vol. 78, no. 5, pp. 3449-3464, 2019.

[19] S. Liu, X. Li, Z. Li, P. Chen, X. Yang, and Y. Liu, "Energy distribution and fractal characterization of acoustic emission (AE) during coal deformation and fracturing," Measurement, vol. 136, no. 3, pp. 122-131, 2019.

[20] X. L. Li, Z. H. Li, E. Y. Wang et al., "Pattern recognition of mine microseismic and blasting events based on wave fractal features," Fractals-Complex Geometry Patterns and Scaling in Nature and Society, vol. 26, no. 3, pp. 1-18, 2018.

[21] S. M. Liu, X. L. Li, D. K. Wang, M. Y. Wu, G. Z. Yin, and M. H. Li, "Mechanical and acoustic emission characteristics of 
coal at temperature impact," Natural Resources Research, vol. 2019, p. 18, 2019.

[22] C. Wang, X. Hou, Z. Liao, Z. Chen, and Z. Lu, "Experimental investigation of predicting coal failure using acoustic emission energy and load-unload response ratio theory," Journal of Applied Geophysics, vol. 161, pp. 76-83, 2019.

[23] Q. Meng, M. Zhang, L. Han, H. Pu, and T. Nie, "Effects of acoustic emission and energy evolution of rock specimens under the uniaxial cyclic loading and unloading compression," Rock Mechanics and Rock Engineering, vol. 49, no. 10, pp. 3873-3886, 2016.

[24] B. Q. Lin, T. Liu, Q. L. Zou, C. J. Zhu, F. Z. Yan, and Z. Zhang, "Crack propagation patterns and energy evolution rules of coal within slotting disturbed zone under various lateral pressure coefficients," Arabian Journal of Geosciences, vol. 8, no. 9, pp. 6643-6654, 2015.

[25] J. Jin, P. Cao, Y. Chen, C. Pu, D. Mao, and X. Fan, "Influence of single flaw on the failure process and energy mechanics of rock-like material," Computers and Geotechnics, vol. 86, pp. 150-162, 2017.

[26] C. P. Lu, L. M. Dou, Y. F. Wang, and T. T. Du, "Microseismic effect of coal materials rockburst failure induced by hard roof," Chinese Journal of Geophysics-Chinese Edition, vol. 53, no. 2, pp. 450-456, 2010.

[27] Y. L. Tan, W. Y. Guo, Q. H. Gu et al., "Research on the rockburst tendency and $\mathrm{AE}$ characteristics of inhomogeneous coal-rock combination bodies," Shock and Vibration, vol. 2016, p. 11, 2016.

[28] T. T. Yu, J. Q. Wang, L. T. Wu, and Y. Xu, “Three-stage network for age estimation," CAAI Transactions on Intelligence Technology, vol. 4, no. 2, pp. 122-126, 2019.

[29] G. Qi, H. Wang, M. Haner, C. Weng, S. Chen, and Z. Zhu, "Convolutional neural network based detection and judgement of environmental obstacle in vehicle operation," CAAI Transactions on Intelligence Technology, vol. 4, no. 2, pp. 80-91, 2019.

[30] Z. J. Wen, X. Wang, L. J. Chen, G. Lin, and H. L. Zhang, "Size effect on acoustic emission characteristics of coal-rock damage evolution," Advances in Materials Science and Engineering, vol. 2017, Article ID 3472485, 8 pages, 2017.

[31] X. P. Zhou and X. H. Li, "Constitutive relationship of brittle rock subjected to dynamic uniaxial tensile loads with microcrack interaction effects," Theoretical and Applied Fracture Mechanics, vol. 52, no. 3, pp. 140-145, 2009.

[32] R.-H. Cao, P. Cao, H. Lin, C.-Z. Pu, and K. Ou, "Mechanical behavior of brittle rock-Like specimens with pre-existing fissures under uniaxial loading: experimental studies and particle mechanics approach," Rock Mechanics and Rock Engineering, vol. 49, no. 3, pp. 763-783, 2016.

[33] D. O. Potyondy, "The bonded-particle model as a tool for rock mechanics research and application: current trends and future directions," Geosystem Engineering, vol. 18, no. 1, pp. 1-28, 2015.

[34] X. Fan, K. Li, H. Lai, Y. Xie, R. Cao, and J. Zheng, "Internal stress distribution and cracking around flaws and openings of rock block under uniaxial compression: a particle mechanics approach," Computers and Geotechnics, vol. 102, pp. 28-38, 2018.

[35] Z. Zhang, H. Xie, R. Zhang et al., "Deformation damage and energy evolution characteristics of coal at different depths," Rock Mechanics and Rock Engineering, vol. 52, no. 5, pp. 1491-1503, 2019. 


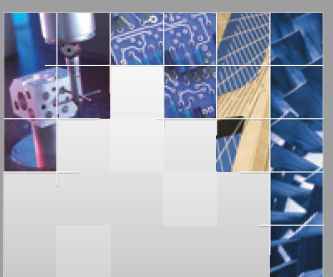

\section{Enfincering}
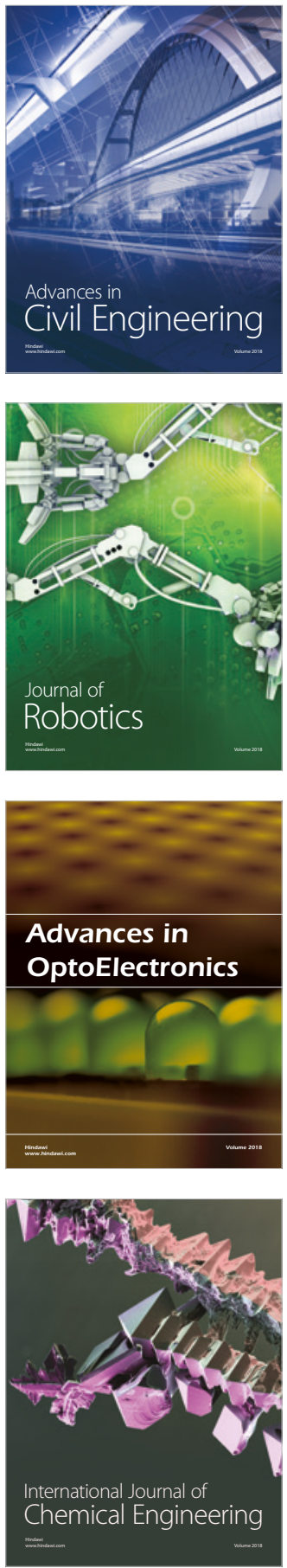



\section{Rotating \\ Machinery}

The Scientific World Journal

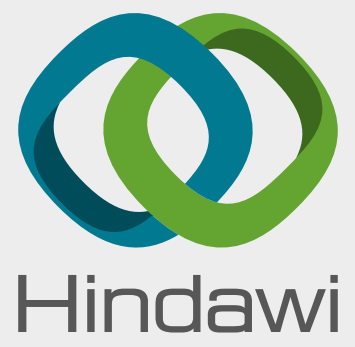

Submit your manuscripts at

www.hindawi.com
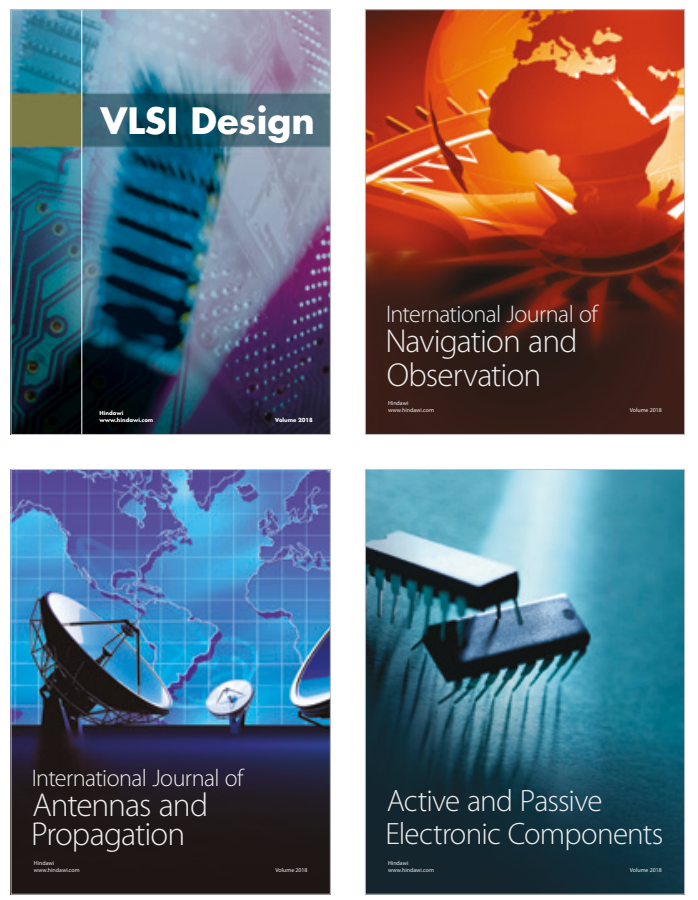


\section{Advances \\ Multimedia}
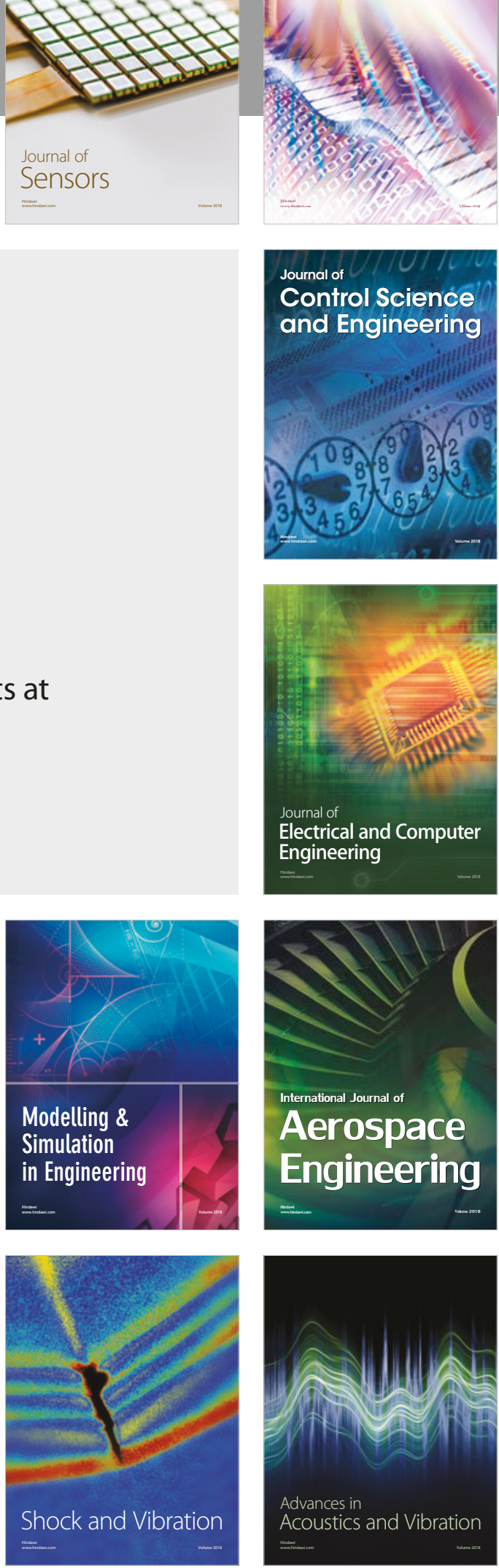